\title{
Dictynna
}

Dictynna

Revue de poétique latine

$3 \mid 2006$

Varia

\section{Erictho und die Figuren der Entzweiung - Vorüberlegungen zu einer Poetik der Emergenz in Lucans Bellum civile}

\section{Alexander Arweiler}

\author{
(2) OpenEdition \\ Journals \\ Édition électronique \\ URL : http://journals.openedition.org/dictynna/202 \\ DOI : 10.4000/dictynna.202 \\ ISSN : 1765-3142
}

Référence électronique

Alexander Arweiler, «Erictho und die Figuren der Entzweiung - Vorüberlegungen zu einer Poetik der Emergenz in Lucans Bellum civile », Dictynna [En ligne], 3 | 2006, mis en ligne le 12 octobre 2010, consulté le 10 septembre 2020. URL : http://journals.openedition.org/dictynna/202 ; DOI : https:// doi.org/10.4000/dictynna.202

Ce document a été généré automatiquement le 10 septembre 2020.

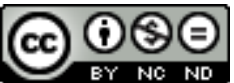

Les contenus des la revue Dictynna sont mis à disposition selon les termes de la Licence Creative Commons Attribution - Pas d'Utilisation Commerciale - Pas de Modification 4.0 International. 


\title{
Erictho und die Figuren der Entzweiung - Vorüberlegungen zu einer Poetik der Emergenz in Lucans Bellum civile ${ }^{1}$
}

\author{
Alexander Arweiler
}

\section{Vorbemerkungen}

1 Im Folgenden möchte ich Überlegungen zur Funktion der Figur der Erictho in Lucans Dichtung Bellum civile mit der Erörterung eines Problems verbinden, das sich in einfache Fragen fassen läßt: Was meinen wir, wenn wir sagen, ein Text handele von etwas? Handelt ein Text in gleicher Weise von einem Gegenstand, der auch eine physikalisch oder historisch beschreibbare Wirklichkeit besitzt, und von einem Gegenstand, der lediglich durch einen Text Wirklichkeit erlangt? Wie kann ein Text von etwas handeln, das erst durch diesen Text entsteht und außerhalb des Textes selbst nur als Abbild in der Vorstellung der Leser existiert? Setzt die Vorstellung, zwischen Text und Gegenstand bestehe ein Abbildungsverhältnis, eine Abhängigkeit voraus? Wenn solche Fragen als selbstverständlich beantwortet vorausgesetzt werden - etwa in gängigen Sätzen der Form "t handelt von x" -, werden wichtige andere Optionen bereits ausgeschaltet, zu denen nicht zuletzt die Möglichkeit gehört, daß ein poetisches Werk nicht-ästhetische Weltkonzepte reflektiert statt sie abzubilden, sie benutzt statt in ihnen zu agieren.

2 Als Begriff, der in fundamental verschiedener Weise das Verhältnis zwischen einem Text und den von ihm generierten Vorstellungen beschreiben läßt, möchte ich daher den der Emergenz vorschlagen. "Emergenz" kann z.B. in der Biologie, Physik oder Soziologie Phänomene bezeichnen, die erst dadurch entstehen, daß Teile in einem Ganzen zusammengefügt sind und daß dieses Ganze Eigenschaften besitzt, die die Teile allein nicht besitzen. Figuren, die in einem Text auftreten, könnten ebenfalls solche 
Eigenschaften besitzen oder selbst emergente Phänomene sein, die in einer topologischen Terminologie als Ekstasen eines Textes verstanden werden können, als Erhebungen innerhalb eines Reliefs, das einen literarischen Text dreidimensional fassen und adäquater beschreiben läßt, als wir es in der gängigen Weise zu tun vermögen. Figuren ragen aus dem Textfluß heraus. Sie sind Verdichtungen, in denen spezifische Konzepte und Probleme behandelt werden können, die ein "normales" narratologisches Modell nicht erfaßt. Der vorliegende Beitrag kann diese Vermutung nicht theoretisch erfassen, er wird aber, so steht zu hoffen, den Blick darauf lenken können, daß Lucans Erictho in einem Verhältnis der Emergenz zu dem sie "enthaltenden" Text steht und der Verfasser sich damit eines ästhetischen Verfahrens bedient hat, das die eingangs formulierte Frage nach dem Gegenstand des Textes umzuformulieren erlaubt: Welche Motive bedingen die Textform derart, daß der Gegenstand - in diesem Fall der Bürgerkrieg - zu einem Mittel wird, ein ästhetisches Anliegen zu exemplifizieren - in diesem Fall, so die These, das der Figur der Entzweiung. Lucans Erictho könnten wir daher als ästhetisch konzipiertes Deutungsinstrument ansehen, das in einem poetischen Kontext die Reflexion auf (konkurrierende) Verfahren historischer, politischer, philosophischer, religiöser oder moralischer Provenienz ermöglicht.

\section{1-a) Figuren}

3 Mit "Figur" bezeichnen wir unter anderem sprachliche Erscheinungen der Wort- und Gedankenfügung (z.B. Stellungsfiguren) und in einem Text begegnende Gestalten der Handlungsebene ("Charaktere", "Personen", "Akteure")2. Beide existieren ausschließlich in Relation zum umgebenden Text. Entsprechend nennt Cicero Figuren und Tropen lumina dicendi, denn sie leuchten aus einem dunkleren Hintergrund hervor $^{3}$. In analoger Weise werden von anderen die Zeichnungen von Personen mit einem Wachsabdruck verglichen, der in einen weichen Untergrund wie ein Siegel eingeprägt ist ${ }^{4}$. Beide treten hervor, ohne daß die Übergangszonen, im Bild die Unterschiede im Helligkeitsgrad oder die Ränder der Wachsabdrücke, deutlich definierbar wären. Eine weitere Gemeinsamkeit besteht in der Eigenschaft der Figuren, Verdichtungen des Sprachflusses zu sein, in denen die Worte als in engerer Beziehung zueinander stehend wahrgenommen werden als diejenigen in ihrer textuellen Umgebung. Figuren, sowohl die lumina dicendi wie die Akteure, sind demnach Verdichtungen innerhalb eines sprachlichen Kunstwerkes. Gleichermaßen sind figurae im Lateinischen Erscheinungsweisen von "etwas", sie lassen es zur Anschauung gelangen und können damit einen Gedanken, ein Konzept oder Thema konkret werden lassen $^{5}$. Diese Eigenschaften des Terminus "Figur" werden im Folgenden genutzt werden, um Erictho als Akteur mit einer Gedankenfigur gleichzusetzen, die als Grundmotiv des Bellum civile gelten kann: der Figur der Entzweiung.

Der wichtigste Akteur des Bell. civ. ist namenlos: der leidenschaftliche Sprecher. Seine Präsenz im Werk dürfte es gewesen sein, die Quintilian dazu veranlasste, Lucans Werk an der epischen Tradition der unbeteiligten Sprecher zu messen und die Lektüre eher den Rednern zu empfehlen, insofern eine von deren Hauptaufgaben gerade die Zeichnung eines erkennbaren Charakters innerhalb ihrer Rede war (vgl. die zentralen Begriffe des ethos und der ethopoiie) ${ }^{6}$. Redner perspektivieren ihre Erzählung, auch die im technischen Sinn bestimmten Abschnitte der narratio, um sich der emotionalen Beteiligung der Zuhörer mithilfe der Gemeinsamkeiten $\mathrm{zu}$ versichern, die diese im 
Erleben des Redners zu finden glauben. Auch Quintilians Vorgänger Cicero hatte eine seiner Dialogfiguren auf die Gemeinsamkeiten zwischen Rednern und Dichtern hinweisen lassen und dabei die übereinstimmenden Interessen in der Ausrichtung der Erfindung (inventio) und Anordung des Ausgesprochenen im Blick gehabt ${ }^{7}$. Während aber der Redner eine Instanz der Fokalisierung sein muß, entledigt sich der Sprecher im Bell. civ. dieser organisatorischen Verantwortung, indem er seine eigene Glaubwürdigkeit immer wieder erschüttert. Er bricht mit dem problematischen Anspruch epischer Erzähler, distanzierte Boten und Berichterstatter zu sein. Sprunghafte Erzählweise, widersprüchliche Darstellungen und Kommentare machen den Sprecher zu einer Figur, die vom Geschehen unmittelbar betroffen ist ${ }^{8}$. Statt am Rande zu stehen, läßt sich der Sprecher von der erlebten Wucht der Ereignisse in seinen eigenen Bericht hineinziehen und überschreitet die Grenzen zwischen Ereignissen, die Wirkungen haben, und seinen Berichten davon derart, daß diese wiederum Wirkungen auf der Ereignisebene zeitigen'.

5 Das "Drama der Sprecherfigur" 10 läßt sich verstehen als eigenständige Handlungsebene, die vor allem in der Auseinandersetzung mit den chronologischen Vorgaben des ihm zum Bericht anvertrauten Stoffes faßbar wird. Auf der Geschehensebene wird der Ausfall sämtlicher Divinationsinstanzen beschrieben, so daß der Sprecher die Deutungsaufgaben übernehmen müsste. Da aber seine Wahrnehmung grundsätzlich auf das Andauern und die Gegenwart ausgerichtet ist, und er Zeitstufen miteinander indentifiziert, erkennt er zwar die in Vorausdeutungen notwendig gedachte Differenz des Zeitlichen, kann ihr aber in seinem Bericht nicht gerecht werden ${ }^{11}$. Wie wir unten sehen werden, vertraut der Sprecher daher die Ausblicke auf eine längst vergangene Zukunft (des Geschichtlichen, dem sein Stoff entstammt) vornehmlich Figuren an, die vom Wahnsinn besessen sind (furor). Er selbst wird aber im Erzählen von den Leidenschaften und dem furor selbst so überwältigt, daß sich ein dauerhafter Konflikt zwischen dem interpretierenden Sprecher und den ihm von der Textstruktur zugewiesenen Aufgaben des Berichts entwickelt ${ }^{12}$. Wenn wir dasselbe aus der produktionsästhetischen Warte des Verfassers formulieren, bedeutet das: Lucan konzipiert einen Sprecher, der sich von den literarischen Vorgaben der Erzähltextanalyse nicht kontrollieren läßt. Damit erfüllt die Sprecherfigur genauso wenig wie die Protagonisten auf der Handlungsebene die zugedachten Aufgaben, und gibt damit den Raum frei, der, wie wir im Folgenden sehen werden, von abstrakten Figuren besetzt und als ästhetische Voraussetzung für die Konzeption der Erictho gesehen werden kann.

\section{1-b) Haupt- und Nebenhandlungen}

Genauso selbstverständlich wie die Rede vom "Wollen des Autors", vom "Gegenstand des Textes" oder von den "Figuren" ist für viele Interpreten die Unterscheidung von Haupt- und Nebenhandlungen, von primären und sekundären Textelementen. Im Kern einer solchen steht eine meist unausgesprochene Hierarchisierung, gemäß der ein einmal definierter Stoff auch den Gegenstand, das Thema und das zentrale Interesse eines Textes bilden, während alle übrigen Elemente unselbständig und stützend sein sollen ${ }^{13}$. Was zur Handlung gehört, erscheint durch sich selbst gerechtfertigt, alles Übrige sekundär und einer Legitimation bedürftig, die meist mithilfe subtiler Funktionszuweisungen durch den "kenntnisreichen" Leser bewerkstelligt werden soll. Sie sollen der Kommentierung dienen, der Deutung, Vertiefung, Spiegelung, 
Widerlegung, Kontrastierung oder ähnlichem ${ }^{14}$. Im Falle des Bellum civile begegneten Klassische Philologen der von ihnen selbst verursachten Zwangslage in der mechanischen Weise, die im akademischen Umfeld am Ende des 19. Jahrhunderts für die Didaktik entwickelt und seitdem unverändert wiederholt wurde: Der Dichter hat eine Haltung zum Krieg, deshalb schreibt er ein Gedicht, und was nicht die Erzählung voranbringt, soll seine politische Haltung als bürgerliches Individuum deutlicher erkennbar machen ("sinnerhellend zu der Deutung des Bürgerkriegs durch Lucan beizutragen") ${ }^{15}$. Die unreflektierte Übernahme vorwissenschaftlicher Kategorien führt dann auch dazu, daß Quantität und Intensität der "Digressionen" nicht zu einer Revision des Ausgangsfehlers führen und zum Beispiel eine Figur wie die Erictho Lucans entgegen der einfachen Leseerfahrung dem schematisierten Koordinatensystem von Haupt-, Neben- und Randelementen untergeordnet und auf die Schnittstelle "Beiwerk/ Randfigur" gestellt wird (nicht Teil des historischen Stoffes, nicht notwendig für den Handlungsfortgang, ohne Kontakt zu einer Hauptfigur, irrelevant für Ausgang und Verständnis der weiteren Ereignisfolge).

7 Eine Beschreibung des Bellum civile kann aber gerade nicht gelingen, wenn die Hierarchie von Haupt- und Nebenhandlung einfach vorausgesetzt wird. Lucans Sprecher verwendet stringent und komplementär zueinander die Verfahren der Entfaltung, Entwicklung und Explikation auf der einen, der Komprimierung, Konzentration und Reduktion auf der anderen Seite, womit er das "Haupt"-Geschehen marginalisieren und den gewonnenen Raum mit "Zusatzelementen" besetzen kann, die zudem über Buchgrenzen hinweg zu selbständigen Textsequenzen vereint werden ${ }^{16}$. Die minutiöse Entfaltung der Einzelphänomene überlagert in der Erinnerung der Leser die Ereignisfolgen des Bürgerkrieges, verzerrt Zusammenhang und Kontinuität des Handlungsablaufes und läßt diesen wie einen brüchigen Rest erscheinen, der Kohärenzerwartungen nicht entsprechen kann ${ }^{17}$. Jede zuverlässige Lektüre des Bellum civile wird daher neu bei den unausgesprochenen Grundannahmen ansetzen müssen, denn deren Unanwendbarkeit dürfte bisher einer der Gründe dafür gewesen sein, daß Leser erst in jüngster Zeit und auch nur vereinzelt die Wirksamkeit haben plausibel machen können, die das Werk bis ca. 1800 entfaltet hat. Ein letzter Hinweis soll noch einer fatalen Allianz aus modernen Literaturtheoretikern, sofern sie über die eigene Zeit hinausblicken können, und Altphilologen gelten, die den Biographismus als naturgegeben betrachten. Bei beiden steht $\mathrm{zu}$ lesen, daß das Bellum civile ein Lebensgefühl des Autors zum Ausdruck bringe. Beide begehen den üblichen Kategorienfehler, lassen aber auch eine Reihe von einfachen Fakten außer acht. Lucans Erzählweise hat klare Vorbilder, sowohl in Homer als auch in der hellenistischen und frühen römischen Epik ${ }^{18}$. Seine Dichtung ist ohne Ovid und Seneca nicht verständlich, weder in ihrer Komposition noch in einzelnen Stellen, an denen die Kenntnis der Vorgängertexte selbstverständliche Voraussetzung für die Deutung ist. Lucans Text steht keineswegs außerhalb aller Traditionen, er ist nicht epochenbezogen reduzierbar, weder einem "Lebensgefühl", "Pessimismus" noch anderen wissenschaftlich nicht beschreibbaren Seelenzuständen des Verfassers oder seiner Zeitgenossen verdankt ${ }^{19}$. Solche Aussagen, wie abgeschwächt auch immer sie vorgebracht werden, beruhen letztlich nicht nur auf methodologischem Desinteresse, sondern auch auf den lange obsolet gewordenen organistischen Modellen lateinischer Literaturgeschichte, in denen Vergils Aeneis ahistorisch, an (ps.)ästhetischen Maßstäben weniger akademischer Klassizisten um die vorletzte Jahrhundertwende herum gemessen, zum 
Gipfel der vorher aufsteigenden und nachher absteigenden Linie eines im Erfolg dürftigen literarischen Bemühens der Römer gemacht wurde ${ }^{20}$.

\section{Raum-zeitliche Identitäten und Differenzen in Bellum civile VI}

8 Als Vorbereitung unserer Analyse der Erictho-Episode soll nun zunächst ein Blick auf den Umgang mit Raum- und Zeitstrukturen im Bellum civile dienen. Diese sind z.B. erzähltechnisch relevant für die Textorganisation, in Erinnerungen, Prodigien, Orakeloder Traumszenen werden sie epistemologisch und ethisch virulent, thematisch begriffen werden sie in der Reflexion auf den Gebrauch und die Zuverlässigkeit raumzeitlicher Wahrnehmungsmuster in verschiedenen Lebensbereichen ${ }^{21}$. Charakteristisch für das Bellum civile ist jedoch, daß raum-zeitliche Relationen vor allem in ihrem Zerfall, ihrer Unbestimmbarkeit oder ihrer Aufhebung präsent sind. So sind Motive der Zeit, die drängt und zur Handlung zwingt, vor allem wegen ihrer Überschreitung der Grenzen zwischen Gegenwart und Zukunft häufig verwendet. Gleiches gilt für die Motive des Raumes, der durch fließende und unsichere Grenzen bestimmt ist. Beide beschreiben mögliche Identitäten von Ereignissen und Personen, die weder mit der Vorstellung eines Voraus- oder Zurückweisens, noch mit Ersetzungsfiguren im Sinne von Metaphern und Bildern erklärbar sind.

9 Auch in dem uns interessierenden sechsten Buch des Werkes werden Erwartungen an geordnete Raum- und Zeitstrukturen enttäuscht ${ }^{22}$. In der Komposition des Werkabschnittes vom Bezug der ersten Lager in bell. civ. 6,1 bis zum Ausrücken aus dem Lager zur Schlacht von Pharsalos in bell. civ. 7,214 dominiert die Retardation der Entscheidungsschlacht, auf die Beteiligte und Leser von Beginn an warten ${ }^{23}$. Die handlungsfortführenden Informationen sind marginalisiert und rekurrent: Dreimal werden Lager aufgeschlagen (6,1f.; 6,13f.; 6,413f.), die ersten beiden als ungeeignet für die geplante Entscheidungsschlacht verlassen, aus dem endgültigen Lager $(6,413 f$.) rücken die Soldaten erst über sechshundert Verse später aus (7,214ff.). Das isolierte Handlungselement, daß die Heere ihre Lager bei Pharsalos errichten $(6,413 f$.), wird von der vorangestellten Topothesie Thessaliens und der folgenden Hinführung zur Nekromantieszene (der Schlaflosigkeit des Sextus) fast vollständig überdeckt. Der Sprecher setzt die Hypotaxe ein, um das lästige Handlungselement seinen Interessen auch grammatisch unterzuordnen (6,413 ubi, vgl. 6,1 postquam).

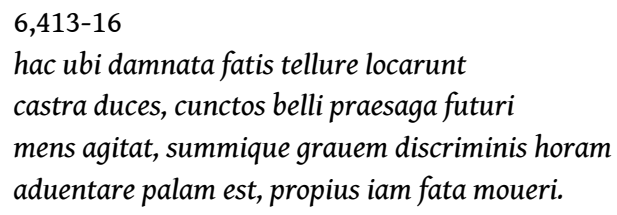

Durch wörtliche (castra duces) und motivische Parallelen zum Buchbeginn lenkt der Sprecher den Blick explizit auf die Überordnung des "Beiwerkes" über die "Haupthandlung" ${ }^{24}$ und nimmt offensiv die Kritik klassizistischer Leser inkauf. Durch die Komposition wird die (bange) Unruhe der Figuren auf die Leser übertragen und zugleich die unzuverlässige Leidenschaft des Sprechers isoliert, der mehrfach fälschlich ankündigt, das Entscheidende auf der Geschehensebene stehe nunmehr unmittelbar bevor (instabat) $)^{25}$. 
11 Daß eine unglückselige Zukunft in die Gegenwart drängt, beunruhigt die Akteure einer Erzählung, die keine Zeit zu kennen scheint. Das Thessaliengeschehen, in dem Erictho auf einem zeitlich unbestimmten Schlachtfeld die Entzweiung des Bürgerkrieges symbolisch und real noch vor der Schlacht von Pharsalos zelebriert, bestätigt und widerlegt zugleich die bange Unruhe, die die Pompeianer bedrängt $(6,414 \mathrm{f}$. cunctos belli praesaga futuri/mens agitat). Die Erictho-Episode ${ }^{26}$ tritt an die Stelle der von Figuren und Lesern erwarteten Schlachtschilderung und besetzt damit den für Pharsalos vorbereiteten Raum des Textes. Die (vielleicht titelgebende) Schlacht ist, gemessen an ihrer Vorbereitung durch den Sprecher, strukturell von ihrem Platz verdrängt worden und durch ein Geschehen ersetzt, das den thematischen Höhepunkt des erhaltenen Werkes bildet. Wie die Frage nach dem zeitlichen Verhältnis zwischen dem Vorzeichen und dem von ihm Bedeuteten, zwischen der Erinnerung an ein Geschehen und der Gegenwart der Erzählung unbestimmt bleibt, so ist es auch die chronologische oder räumliche Differenz zwischen Vorahnung bzw. Traumgesicht und Geschehen. Markiert durch wörtliche Parallelen (8,43f. Tristes praesagia curas/ exagitant) komplementieren die Traumgesichte Cornelias die Unruhe der Pompeianer, so daß auf der Handlungsebene die geahnte Zukunft zwar nunmehr in der Vergangenheit liegt, im Text beide aber gleichzeitig erscheinen ${ }^{27}$. Die beteiligten Figuren ahnen nur in übertragenem Sinne, denn die Ereignisse sind sowohl in der Zeit des Textes als in der historischen Zeitrechnung längst vergangen. Für das Erleben Thessaliens sind Zeitstufen irrelevant ${ }^{28}$. Jede Nacht ist Cornelia in einem Thessalien, das die Wirklichkeit noch übertrifft. Thessalien als totum pro parte evoziert den Komplex des sechsten Buches, dessen Präsenz mit dem Abgang der Erictho von der Ereignisebene nicht unterbrochen wurde ${ }^{29}$. Für die Akteure wie für die Leser wandeln die Imaginationen des Vergangenen, der fernen Orte oder Zeiten die Differenz, die Zeitstufen kennzeichnet, in hyperbolisch wahrgenommene Identitäten, die das Wirkliche in das Erleben der Vorstellung verlegen $(8,45 \text { Thessaliam nox omnis habet })^{30}$.

\section{Thessalien als poetischer Raum}

Das Fundament der Erictho-Episode bildet die Landschaftskonstruktion Thessaliens, die im echten Sinne der poetischen Topothesie nicht in eine Ekphrasis verschoben, sondern zur Handlungsebene gezogen ist $^{31}$. Aus Einzelteilen setzt Lucan eine unbestimmbare Landschaft zusammen, in der die durch Regeln, Traditionen und Sprachen unterschiedenen Wissensbereiche (Geo- und Ethnographie, Kosmologie, Mythos, Geschichte) $z u$ einem poetischen Konzentrat verdichtet $\operatorname{sind}^{32}$. In der Konstruktion werden unterschiedslos Elemente verwendet, die nur innerhalb der einzelnen Diskurse als gesicherte Tatsachen gelten. Im poetischem Amalgam haben sie die Legitimation durch die diskursimmanenten Regeln verloren, so daß ihr Informationsgehalt unbestimmt wird ${ }^{33}$. An die Stelle der geordneten Deskription setzt der Sprecher dynamische Ausdrücke und entwirft eine Landschaft, die in Bewegung, gleichermaßen von Bergen eingeschlossen und selbst eine nach oben drängende Fläche ist. Dieses Land soll aus Sümpfen emporgestiegen sein, aber die Bewegung ist nicht abgeschlossen, wie der mehrfache Einsatz des Berichtes beim selben Ausgangszustand zeigt $^{34}$. Die Konsistenz ist unbestimmt (Wasser, Erde, Sumpf) und entspricht darin der geschilderten Auflösung der Grenzen zwischen Ober- und Unterwelt. Das Land ist wenig mehr als eine schwimmende Unterlage, auf der Bewohner und Besucher wie 
schattenhafte Figuren agieren. Selbst die markierten Zitate aus naturwissenschaftlichen Werken, etwa in der Frage, wie sich Ossa und Olymp voneinander getrennt haben, dienen dazu, sich von der behaupteten Eindeutigkeit dieser Erklärungsmodelle abzusetzen ${ }^{35}$.

Isolierte Zitate geographischen Wissens sowie der Gebrauch fachwissenschaftlicher Elemente und Beschreibungsverfahren sollen keine sichere Kenntnis hervorbringen. Sie erwecken im Gegenteil Zweifel und Unsicherheit über den ontischen Status dieser Landschaft. Das Konstrukt soll als solches erkannt und als imaginärer Gegenentwurf zu nicht-poetischen Deskriptionen wahrgenommen werden ${ }^{36}$. Der thessalische Raum ist aus der Perspektive anderer Wissensdisziplinen unmöglich, nicht bereisbar und ein Konglomerat widersprüchlicher Details ${ }^{37}$. Daß die Landschaftsschilderung dennoch eine Kohärenzillusion erzeugen kann, beruht, in der Terminologie der Semiotik gesprochen, auf den Konnotationen, die die Leser den sprachlichen Zeichen zuordnen, indem sie nicht auf die Unvereinbarkeit der Denotate, sondern auf die ihnen in der literarischen Imagination zugesprochenen Bedeutungen achten ${ }^{38}$. Poetisches Desinteresse an erfahrbaren Gegebenheiten, wie sie die offizielle Geographie versammelt, ist ein bekanntes, für die Eigenständigkeit poetischer Erkenntniswege konstitutives Phänomen ${ }^{39}$. Entsprechend ist in Lucans Flüssekatalog nicht die Topographie Thessaliens Bezugspunkt der Mimesis, sondern allgemein Texte, die den Materialfundus "Flüssenamen und ihre mythisch-geographischen Konnotationen" bearbeiten, im Besonderen Ovid ${ }^{40}$.

Obwohl also manche Elemente denen entsprechen, die Fachgelehrte als relevant erachten (Reisende, Geographen, Enzyklopädisten, Historiographen), ist deren Kombination im poetischen Text eigenständig. Die Regeln der Kombination von Wissenselementen und Vorstellungen variieren gemäß den Konventionen der Gelehrtengemeinschaft und lassen z.B. Assoziation, Analogie oder Gleichzeitigkeit entweder als gültige Relationsbestimmungen zu oder schließen sie aus ${ }^{41}$. Das Wissen um die Geschiedenheit dieser Kombinationsregeln und der von ihnen erzeugten Wissensmodelle wird im Bellum civile mehrfach an der Kontrastierung des gelehrten Wissens mit dem Mythologischen vorgeführt, insbesondere durch das der Tradition der Lehrdichtung entnommene Instrument der "multiple explanations"42. Wie sich im Abschluß des genannten Flüssekataloges zeigt, macht der Sprecher nicht nur auf die willkürliche Anordnung seiner "Geographie" aufmerksam, sondern stellt auch die Auswahlkriterien heraus, nach denen er diese entwirft.

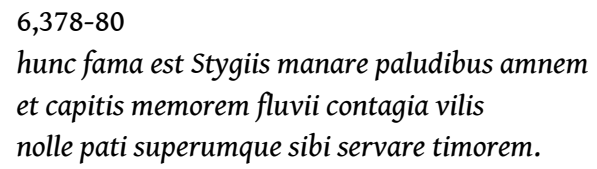

Der Titaresos wird mit der Unterwelt in Verbindung gebracht und bringt ein heterogenes Element in den Katalog, der sich zunächst nur der zuverlässigen Beschreibung oberirdischer Landschaft $\mathrm{zu}$ widmen schien ${ }^{43}$. Dem Fluß eignet die Fähigkeit der Erinnerung an die Ursprünge (memorem), und seine chthonische Macht, die Überirdischen an ihren Eid zu binden, beruht auf der aktualisierenden Kraft der Erinnerung, die die Vergangenheit in die Gegenwart bringt. Für diese Deutung der Erinnerung als einer Durchbrechung der Chronologie, durch die Thessalien aus dem Herrschaftsbereich der superi entfernt wird, beruft sich der Sprecher auf ein Gerücht (fama est), das gleichermaßen die Quelle seines Wissens - die literarische Tradition bezeichnet und die Zuverlässigkeit seiner Aussage behauptet" ${ }^{44}$ Die "affektierte 
Unwissenheit" ist die selbstsichere Behauptung einer eigenen Wahrheitsfähigkeit der Dichtung, in der Thessalien aus raum-zeitlicher Ordnung herausgehoben ist ${ }^{45}$.

Mythologisch ist Thessalien, wie Pomponius Mela feststellte, überreich belegt, so daß der Sprecher mühelos eine Auswahl und Perspektivierung auf das Leitkonzept der damnata tellus hin bewerkstelligen kann, ohne zu leugnen, daß sich viele Konnotationen auch konträr entwickeln lassen könnten ${ }^{46}$. Die Präsenz der chthonischen Mächte kennzeichnet Thessalien als Landschaft, die sich der Differenz von "oben" und "unten", "irdisch" oder "unter-/ oberirdisch" entzieht. Thessalien ist nicht eine Landschaft, die lediglich erstaunliche Eigenschaften aufweist, sondern eine Vorstellung außerhalb der Geschehensebene, die von dem Drängen der Unterwelt nach oben hervorgebracht wird. Der Sprecher lokalisiert es mithilfe des Verfahrens der illustratio und entfaltet das Bündel regional bezogener Mythenelemente, z.B. des Gigantenkampfes, in eine Hyperbel, die vor allem als Figur der Wiederholung den metaphysischen Grund der Katastrophe beschreibt. Der Ort ist eine Bedingung des zu schildernden Verbrechens und bildet darüber hinaus dessen inneres Wesen, indem er gleichzeitig den Hintergrund der Handlung und ihren Beweggrund zur Anschauung bringt. Es findet im späteren Handlungsverlauf nicht nur deshalb kein Ortswechsel in die Unterwelt statt, weil das dichte Verweisnetz auf die literarischen Traditionen der Katabaseis dies überflüssig machte, sondern weil das Chthonische selbst nicht als getrennt von dem Schauplatz menschlicher Handlungen gedacht wird.

6,357-69

(monstrat Echionias), ubi quondam Pentheos exul

colla caputque ferens supremo tradidit igni

questa quod hoc solum nato rapuisset Agaue.

17 In der mythischen Vorgeschichte Thessaliens (quondam) hat Agave fern der Heimat (exul) Kopf und Hals ihres Sohnes Pentheus hier dem Feuer übergeben, klagend, daß sie von ihrem Sohn nicht hatte mehr mit sich reißen können ${ }^{47}$. Damit vermerkt der Sprecher aber zugleich die Umstände des Endes des Pompeius und die grausame Unzufriedenheit Caesars mit dem unzureichenden Geschenk, das ihm der Ägypter (später, früher) macht ${ }^{48}$. Wörtliche Übereinstimmung sowie Parallelen der Konstellation und Motivik (Abtrennung von Kopf und Hals, [halbvollzogene] Verbrennung) verlegen die außerhalb von Thessalien in einer späteren Buchpassage zu schildernde Tötung des Pompeius ${ }^{49}$ in die Vergangenheit des jetzt zu schildernden Schauplatzes, wo sich dasselbe nicht nur schon ereignet hat, sondern wo es im Moment der Erzählung präsent ist. Es werden also die Identifikationen im Räumlichen fortgesetzt (Ägypten, Theben ${ }^{50}$, Thessalien), die schon in der Kombination konkreter Geographica sinnfällig wurden. Diese Identifikation von Zeitstufen und Ereignissen ist nicht mit der (üblichen) Klassifikation als erzähltechnischer Vorverweis erklärt, denn dessen Schema hält ja gerade die Trennung der Zeitstufen aufrecht. Die mythische Vergangenheit (Agaue) ist aber die historische Vergangenheit (Bürgerkrieg, Pompeius), und das textlich Zukünftige ist bereits Geschehenes.

$6,393 \mathrm{f}$.

teque, senex Chiron, gelido qui sidere fulgens

inpetis Haemonio maiorem Scorpion arcu.

Wie die Antagonisten Pompeius und Caesar in der Exposition des ersten Buches über die Abstraktionen von alternder Starre und ungezügelter Energie mit den Bildern von Blitz und Eiche in das werkmotivierende Spannungsverhältnis gebracht wurden ${ }^{51}$, so finden sich in der Sternenkonstellation von Chiron und Skorpion sowohl die Grundlage 
des historischen Konflikts als auch dessen auf der Ereignisebene erreichter, "aktueller" Zustand bereits vor der historischen Zeit verwirklicht ${ }^{52}$. Das als dynamische Ausgangsposition einer Handlung beschriebene Verhältnis der Gestirne (impetis) ist Ikon der Gegner in Kampfesstellung (vgl. 6,2 par), in dem die Chiffren des Alters (senex) und des kalten Sterns (gelido sidere) Chiron / Pompeius vertreten ${ }^{53}$, während der Scorpion / Caesar die unbändige Ausbreitung seines Machtbereiches (maiorem) sucht ${ }^{54}$. Wiederum findet sich kein Schema der Trennung, etwa eines Prodigium oder einer sympathischen Reaktion des Kosmos, in denen vorausweisende Bilder und Deutungen des menschlichen Tuns ausgedrückt würden (vgl. 7, 151f. venturos prodere casus/ per varias Fortuna notas). Darin findet lediglich eine momentane Veränderung der sichtbaren Welt statt, in der das Entstehen neuer Zeichen (7,203 nova signa) wegen der prinzipiellen Lesbarkeit der Naturerscheinungen der zeitlichen Ordnung verpflichtet bleibt ${ }^{55}$. Prodigien unterscheiden zwischen dem Zeichen und seiner Bedeutung, während in Thessalien die Sternenkonstellation dauerhaftes Bild der einander bedrohenden Kriegsparteien ist, und wie die Schilderung der Hexenkünste zeigt, der Wandel und das Entstehen von nova nicht eine Unterbrechung des Dauerhaften, sondern selbst das Beständige sind. Durch ein Selbstzitat aus dem Heereskatalog (3,191-98) in der Besiedlungsgeschichte Thessaliens $(6,381-85)^{56}$ verdichtet der Sprecher symbolisch die Vorbereitungen zur Schlacht in seinem Text zu einem Moment der Geschichte Thessaliens, in der das aktuelle Geschehen bereits stattgefunden hat, zugleich aber gegenwärtig ist.

Daß es sich, in Analogie zur "geographistischen" Übercodierung der Landschaft, auch bei der Schilderung der kosmischen Anlage Thessaliens um ein irritierendes, Zweifel am Denotat weckendes Konstrukt handelt, kann ein erzählerischer Kunstgriff belegen, den der Sprecher im Katalog der Hexenkünste anwendet:

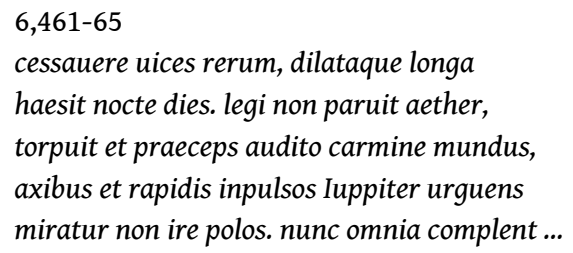

Die Schilderung der auf den Kosmos wirkenden Hexenkünste beginnt mit der apokopierten Form cessavere, die in der epischen Sprache als feierliches Signal der Rückkehr zu bedeutenden Elementen der Ereignisfolge verbreitet ist, hier aber wie ein nachwirkendes Ergebnis einer vergangenen Handlung etwas vorstellt, was eine dauerhafte Möglichkeit im Katalog habitueller Fähigkeiten bezeichnen soll ${ }^{57}$. Darüber hinaus wird die Genese Thessaliens als Werk der (magischen) Worte dargestellt, sie ist Produkt der Sprache der Hexen und des Dichters, der mit dem Zitat des vergilischen Aeneisprooems (6,483 tantae molis onus percussum voce recessit) die Gründungsgeschichte Roms durch dessen späteren Gang nach Thessalien widerrufen sieht und für seine Hexen auch die Macht literarischer aemulatio reklamiert ${ }^{58}$. Die Präsentation des Kataloges als einer Ereignisfolge erlaubt es dem Dichter, das Herausfallen des Landes aus dem Weltenlauf zu behaupten und es in seiner paradoxen Natur allein auf die Wirklichkeit des Textes zu gründen ${ }^{59}$. Thessalien ist durch die fata zur verdammten Erde (damnata tellus) gemacht worden (vgl. 6,332 bello quam fata parabant), wobei sich diese Bestimmung wiederum nicht durch einen Vorausblick auf das vergangene, auf der Erzählebene zukünftige Geschehen erklärt, sondern schon in der Natur des Landes verankert gewesen sein soll ${ }^{60}$. Die Seinsbedingung des Landes ist der Text, der über eine 
historisierende Kosmologie und mythisierende Historie ontologische Prämissen mißachtet und den Raum lediglich in einem zeitstufenlosen Feld zwischen Ereignissen (Schlacht) und Bedingungen (Kosmos, Besiedlung, Geographie) ansiedelt. Das Geschehen folgt den Vorgaben der Natur, ist aber bereits in der Natur des Landes enthalten, eine Kenntnis, die sich nur dem Dichter zeigt, der die bei der Erklärung des tatsächlichen Geschehens und der ihm zugrunde liegenden Figuren erfolglosen Wissensordnungen durch das Interesse an ästhetischer Erkenntnis ersetzt.

\section{Diskussionen von Differenz und Identität in der Vorbereitung der Erictho-Episode}

21 Im Unterschied zu der Vorstellung, der Text lasse sich durch den Nachweis des Wissens oder Unwissens des Verfassers hinsichtlich geographisch oder chronologisch konstruierter Tatsachen erklären, gehen wir also davon aus, daß im Bellum civile die Bedingungen zum Thema gemacht werden, unter denen raum-zeitliche Identität oder Differenz wahrgenommen und als gültig betrachtet werden. Diese reflektierende Position gegenüber den Differenzen erlaubt es dem Sprecher, für in anderen Wissensordnungen unterschiedene Szenarien eine im Erleben gründende Identität zu behaupten und sie als tatsächlich dasselbe, nicht als in der Relation eines Verweises stehend zu behandeln. Die Schauplätze in Thessalien sind, kenntlich in der Präsenz der Totengeister (6,650 manes. 653 umbras) und der jederzeit möglichen Rückkehr von Toten ins Reich der Lebenden, unabhängig von der Chronologie menschlichen Daseins und unabhängig von der vertikalen Gliederung der Erfahrungswelt (ober-/ unterirdisch) ${ }^{61}$.

Den Lesern ist die Vorstellung, daß die Trennung zwischen Tod und Leben und den ihnen zugewiesenen Räumen aufgehoben werden kann, bereits aus den Erinnerungen des alten Mannes an den Bürgerkrieg unter Marius und Sulla bekannt: Gräberfelder waren voller Flüchtlinge, die sich bei den Toten Zuflucht erhofften (2,152 busta repleta fuga) und tote Körper vermischten sich mit lebendigen (2,152f. permixtaque viva sepultis/ corpora $)^{62}$. Als hyperbolische Schilderungen auf der Ereignisebene wären diese Motive unterbestimmt ${ }^{63}$. Die Aufhebung der Differenz ist eine Bedingung des Geschehens, und entsprechend können Akteure und Leser nicht einem Geschehen die Funktion der Bezeichnung, einem anderen die des Bezeichnetwerdens zuordnen. Denn dafür müssten sie die Hinweise darauf außer acht lassen, daß in Thessalien (wie in der Erinnerung des alten Mannes) beide zusammenfallen und die Schilderung auf sich selbst als das Unheil verweist ${ }^{64}$. Wie der Text verweist auch die im Folgenden auftretende Figur der Erictho auf sich selbst als Zeichen, das nur selbstreferentiell lesbar ist ${ }^{65}$. Diese Selbstreferentialität der poetischen Konstruktion, die den Leser von der mimetisch inspirierten Lektüre eines Vergleiches mit Erfahrungswirklichkeiten zu einer innertextuellen Analyse der Darstellung als Entfaltung von Figuren leiten soll, findet in der Aussage des Sprechers, daß Thessaliens Bewohnerinnen die Kräfte der Poesie übersteigen, einen expliziten Ausdruck ${ }^{66}$.

$6,436 f$.

Haemonidum, ficti quas nulla licentia monstri

transierit, quarum, quidquid non creditur, ars est.

Die Hexen haben eine poietische Kunst entwickelt, die das traktiert und hervorbringt, was Sprecher und Leser nicht innerhalb der ihnen verfügbaren Wissensordnungen 
imaginieren können (non creditur). Der Sprecher versucht sich nach eigenen Worten an etwas, das nicht einmal eine völlig entfesselte poetische Imagination einholen könnte, an wahren Ungeheuern, die die erfundenen übertreffen und deren Erfinder der Unfähigkeit überführen. ${ }^{67}$ Die hier behauptete Wahrheit ist immer monströser als das, was sich die Dichter an Monströsem vorzustellen fähig sind, und dennoch ist der Wettstreit um die bestmögliche Anwendung der ars nicht einseitig zuungunsten des Sprechers für die Hexen entschieden. Schließlich mißt sich der Sprecher vor allem an den literarischen Traditionen, die es ihm ermöglichen, das professionalisierte Movens der "Überbietung der Vorgänger" selbst zum Gegenstand zu machen und eine transzendentale Untersuchung anzulegen: Gesetzt den Fall, es gäbe eine Wirklichkeit, die immer schon die Imagination der Dichter übersteigt, welche Folgen ergeben sich dann für die Möglichkeit, poietisch zu handeln? Eine noch kaum gesehene Option scheint dem Sprecher des Bellum civile besonders einleuchtend zu sein, nämlich die Hyperbel und die Steigerung so weit $\mathrm{zu}$ treiben, daß Überbietung selbst als unangemessenes poetisches Motiv und Erfindung irregeleiteter Leser erscheint. Und richtig: Welche ästhetische Legitimation haben poetische Werke, die nichts anderes im Sinne hätten als Längenvergleich und Siegerposen? Wenn sich der Sprecher immer neu an der Überbietung seiner selbst und der sprachlichen Vorgaben versucht, handelt er tatsächlich im Einklang mit den Hexen, mit Caesar oder auch Cato; ästhetisch relevant ist aber die Untersuchung der hyperbolischen Form, die Beobachtung ihrer Anwendung kann nur der Beginn der Analyse sein.

Was die Bewohnerinnen mit dem Land Thessalien gemeinsam haben, ist die Überschreitung von begrenzenden Definitionen. Sie übersteigen die sprachlichen und begrifflichen Möglichkeiten wesentlich, was bedeutet, daß sie ihre Wirklichkeit dem Akt der Überschreitung verdanken (transierit). Das Wesen von Land und Hexen ist die Überschreitung, ohne die sie nichts wären als die üblichen monstra ficta der Literaten. Deshalb ist es wichtig zu sehen, daß wir es nicht mit einfacher Steigerung von bereits Bekanntem zu tun haben. Die Haemonides sind nicht, wie meist angenommen, einfach nur größer, monströser oder unheimlicher als andere vergleichbare Figuren. Sie sind Figuren des Überstiegs, und dies in der doppelten Bedeutung von Figur als "Gedanke" und "Akteur". Für diese Figuren als Akteure gilt ebenfalls, daß in ihnen Zeichen und Bezeichnetes zusammen fallen, wie wir es oben schon gesehen haben und wie es auch in der späteren Nekromantieszene zur Gänze auf der Handlungsebene expliziert wird. Die Suche nach der Botschaft, die der Tote zu überbringen hat, endet mit der Erkenntnis, daß die Botschaft inhaltsleer ist und nur auf sich selbst als Botschaft verweist ${ }^{68}$. Wie Thessalien, die Hexen, der das Scheitern der Hyperbel imaginierende Sprecher oder Erictho ist auch der Tote ein selbstreferentielles Zeichen, das nichts außer sich selbst als Form (oder eben: Figur) transportiert ${ }^{69}$.

Bevor wir im nächsten Kapitel auf die Relationen eingehen, die diese Figuren untereinander und mit dem umgebenden Text verbinden, und diese als Indizien für das vom Dichter anvisierte Phänomen der Emergenz deuten, soll ein weiteres Beispiel raum-zeitlicher Differenzleugnung diskutiert werden, das die Ericthoszene gedanklich entscheidend prägt. Der Sprecher hatte, wie in Kap. 2 gesehen, durch ungeduldige Vorverweise den Raum der zweiten Hälfte von Bell. civ. 6 für die Schlacht von Pharsalos reserviert, füllt ihn dann aber in Enttäuschung der Erwartungen mit der Ericthoszene. Dies geschieht aber erst, als er erneut den Eindruck erweckt hat, er habe seine ursprüngliche Idee wieder aufgenommen. Nachdem sich Sextus und Erictho auf eine 
Nekromantie als den rechten Weg der Zukunftsbefragung verständigt haben, spricht die Hexe zum Erstaunen der Leser nämlich von zahlreichen Getöteten auf den emathischen Feldern (6,619f. cum tanta novae sit copia mortis,/ Emathiis ... campis), preist die Vorzüge eines noch warmen Körpers (6,621 modo defuncti tepidique cadaveris), verdunkelt durch ihre Kunst (arte) die Nacht und zieht los, um ein geeignetes Opfer zu suchen $^{70}$. Diese Aussage, daß die Hexe auf einem Schlachtfeld tätig wird, das es noch gar nicht geben soll, ist mehrfach diskutiert worden. ${ }^{71}$ Im Folgenden werde ich vorschlagen, keine abschwächenden Verweisrelationen anzunehmen, sondern im Einklang mit den bisherigen Beobachtungen eine eindeutige Behauptung von Identität zwischen dem hier genannten und dem später zu schildernden Schlachtfeld anzunehmen. Das eine ist kein Symbol für das andere, sondern dasselbe.

Mehrere motivische Rahmen werden innerhalb der Erictho-Szene eröffnet und erst nach dem Ende der Schlacht im siebten Buch geschlossen. So ist das Motiv der verweigerten Bestattung (6,626 tumulus negatis) hier nur genannt, in der Beschreibung der Frevel Caesars im siebten Buch wird es entfaltet ${ }^{72}$. Die Motive der Verbrennung der Leichen durch die Sonne und die szenische Konstellation, in der eine monströse Figur die Toten mustert (Erictho / Caesar), verknüpfen das Geschehen des sechsten mit dem des siebten Buches ${ }^{73}$. Am Beginn der Ericthoszene fliehen die Aasfresser vor der Hexe (fugere lupi), am Ende der Schlacht im siebten Buch $(7,825-46)$ kehren sie zurück (venere lupi) und auch der Sieger selbst wird von den Toten vertrieben (7,824 victore fugato). Das Werk der Erictho an den Körpern, die sie zerstört, wird von den Tieren nach dem Ende der Schlacht fortgesetzt ${ }^{74}$. Schließlich zweifelt Erictho nicht daran, daß der Tote, den sie für die Wiederbelebung vor der Schlacht benötigt, ein Pompeianer sein soll - ein erster Hinweis auf ihre ambivalente Verbindung zur Pompeianerseite, in deren Lager sie am Ende des Geschehens verschwinden wird! ${ }^{75}$. Wenn nun ein toter Pompeianer Auskunft über den zukünftigen Schlachtverlauf geben soll, welcher wäre dann besser geeignet als einer, der diese Schlacht schon erlebt hat? Wie hoch ist entsprechend die Beweislast dessen, der behauptet, zwar seien die Requisiten identisch, nicht jedoch der Kontext, aus dem diese entstammen, nämlich das Schlachtfeld vor der Schlacht und danach? Es handelt sich um eine Prolepse, die sich von ihrer gängigen Form in der Semantik der Wortverbindungen nur durch ihren Umfang unterscheidet.

Ein weiteres Indiz dafür, daß wir es auch bei den Schlachtfeldern mit dem poetischen Interesse an Identifikation zu tun haben, das wir für das Bellum civile beobachtet haben, läßt sich aus dem Umgang mit Pharsalos und Philippi gewinnen. Die immer noch verbreitete Erklärung der Kommentare, daß die unabsichtliche oder aus Desinteresse entstandene Vertauschung von Pharsalos und Philippi bei römischen Dichtern geläufig sei, ist schon von Schrempp (1964) erheblich modifiziert worden ${ }^{76}$. Im Bellum civile teilen sich Sprecher und Figuren die Ungeduld, die sie Ereignisse, Orte und Gedanken immer wieder zusammenziehen und ineins setzen läßt, dies geschieht aber mit benennbaren Absichten, die sich auch für die Vertauschung der Orte und jeweiligen Geschehen zeigt. Der Sprecher warnt ja auch Brutus (7,591f.), sein eigenes Thessalien abzuwarten und nicht Philippi zur Unzeit (ante) herbeizuholen (admoveris) 77 . Den Grundstein für die Identifikation legt aber bereits die Vision der Besessenen zum Abschluß des ersten Buches (1,678-694). Sie sieht (video) den Verlauf des Krieges bis zur Ermordung Caesars vor sich - in weiten Teilen also das Inhaltsverzeichnis des Werkes ${ }^{78}$ -, und rahmt ihre metapoetische Ankündigung mit dem Signalwort Philippi. 


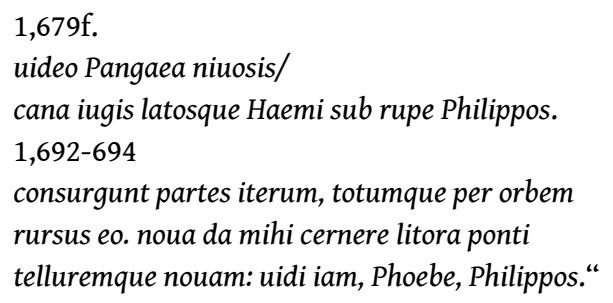

Mit den Hexen teilen sich die Dichter die Kunst, mit den Wahnsinnigen aber das Desinteresse an den Regeln und die Überforderung in der Suche nach Bedeutung (wir könnten die Hexen der Syntax, die Besessenen der Semantik zuordnen). Die Semantik der Ortsnamen wird von beiden entsprechend anders konzipiert als von Lesern, die die geographische Zuordnung privilegieren oder als selbstverständlich annehmen ${ }^{79}$. Die Identifikation ist aber nur verständlich, wenn der Sprecher (bzw. die Frauenfigur) sich über die Differenz aus geographischer Perspektive im Klaren ist. Die Endstellung von Philippos erhält nur aus der absichtlichen Mißachtung dieser Perspektive den gewünschten Sinn, indem das zunächst als Phänomen der Wiederholung (iterum, rursus) Bezeichnete nunmehr ein Phänomen der Gleichheit ist. Die Vision der Frau, die auf den weiteren Werkverlauf blickt, ist zugleich die Form des Sehens (videre) von unerhörten Landschaften (nova litora, nova tellus) ${ }^{80}$, die der Sprecher selbst zu beschreiben sucht, wenn er die Verbindungen zwischen raum-zeitlich und ontologisch unvereinbaren Dingen so gestaltet, daß ihre Wahrheit daraus hervorgeht, die Wahrheit nämlich, die seiner Aussage nach die Möglichkeiten der Imagination uneinholbar übersteigt (quam nulla licentia transierit).

\section{Emergenz der Figuren und die Landschaft als Akteur}

Bewegungen der Konzentration führen den Leser von Thessalien auf das Feld aufgebrochener Gräber in der Nähe des Lagers, wo die Diener umherschweifen $(6,574$ vagati), nach der Verabredung zur Nekromantie auch Erictho den Toten sucht $(6,625$ pererrat), schließlich zu einem abgeschlossenen Ort in der Tiefe eines hochragenden Berges $(6,640$. montisque cavi [...] alta sub rupe), wo sich in tiefer Dunkelheit der Erdboden nach unten neigt (6,643 in praeceps subsedit humus) und einen Abgrund bildet, an dem Unter- und Oberwelt so sehr ineinander übergehen, daß der Erzähler nicht sagen kann, ob die Hexe den Totengeistern begegnet, weil diese heraufgestiegen sind oder die Hexe herab ${ }^{81}$. Die Informationen machen die Bezeichnung von Grenzen $(6,649$ mundi confine latentis) zu paradoxen Ausdrücken, die der bereits paradoxen Wirklichkeit nicht entsprechen, so daß der unschlüssige Sprecher die Gegebenheiten nur zur Kenntnis nehmen, aber nicht deuten kann (6,652 dubium est $)^{82}$. In Entsprechung zu diesen und verwandten Kennzeichnungen der Räume stehen die zahlreichen Motive, die die Bewegung der Figuren in diesen Räumen als ziellos, irrend und ungerichtet beschreiben, und beidem entspricht auch die Allgegenwart Caesars in der Schlacht, denn in einem paradoxen Raum ist eine monströse Figur wie Caesar auch der Notwendigkeit der Präsenz jeweils an einem und nur einem Ort enthoben. In einem solchen Raum scheint es vergeblich, durch physischen Ortswechsel der Beherrschung durch die metaphysische Natur des Ortes entkommen zu wollen ${ }^{83}$.

In monotoner Rekurrenz nennt der Sprecher immer wieder Thessalien beim Namen und unterstreicht mit dem Nachdruck der Deixis die enge Verbindung zwischen Land 
und geschildertem Geschehen (hac tellure, hic, hunc etc.) ${ }^{84}$, bis schließlich aus der dynamischen Konstruktion ${ }^{85}$ des Landes die an es gebundenen Figuren Sextus und Erictho hervorgehen. Thessalien nimmt den Charakter einer handelnden Figur an. Es verstärkt (adiuvat ipse locus) die Anlagen des Sextus zum Wahnsinn (vanum saevumque furorem), und der an den Ort gebundene Ruf der Erictho (fama loci) ${ }^{86}$ vermittelt die spätere Begegnung, indem er für Sextus Erictho hervorbringt (hanc prodidit), wie es prägnant für "Kunde von Erictho" heißt ${ }^{87}$. Daß sich die Kunde von Erictho nur auf den Ort bezieht (fama loci) ist literaturgeschichtlich gerechtfertigt durch den Mangel an Vorbildtexten, produktionsästhetisch scheint die Figur Erictho damit auf das Engste an den Ort gebunden $z u$ werden, aus dem sie emporsteigt ${ }^{88}$. Die dynamische Konzeption des Ortes läßt das Hervorkommen der Erictho aus diesem Text, und nicht aus der literarischen fama, beinahe organisch erscheinen. Der Text produziert (in seiner Anlage, den Interessen seiner Figuren, der Sprache) zunächst das Land als handelnde Figur, schließlich daraus auch die Protagonisten der Folgeszene und ihre Begegnung. Wie sich Berge oder im Reliefbild Darstellungen von der geraden Fläche abheben, stehen die mehrfach geschilderten Bewegungen, die das Land hervorbringen, in einer zunehmenden Abstraktion, an deren Spitze Erictho zum Vorschein kommt ${ }^{89}$. Die Protagonisten der Nekromantie-Szene gehen aus der Landschaft hervor (Sextus, Erictho, die Toten, der Tote) und stehen im Verhältnis der Emergenz zu den übrigen Handlungselementen. Hier sind Figuren über ihre Konstruiertheit hinaus als Ekstasen des Textes gefaßt, aus dessen Untergrund sie sich erheben, in genauer Entsprechung zu den Bewegungen in der geschilderten Landschaft ${ }^{90}$. Wollten wir an den Modellen festhalten, die in der Formulierung " $t$ handelt von $x$ " zum Ausdruck gebracht werden, müssten wir entsprechend sagen, daß hier die Landschaft den Text abbildet, nicht der Text die Landschaft.

31 Der für die Ereignisfolge des Bell. civ. irrelevante Sextus Pompeius wird vom Betroffenen selbst genauso wie vom Sprecher als bloßer Teil einer Menge bezeichnet (turbae mixtus inerti, turbae pars ego), aus deren allgemeiner Angst er wie ein emergentes Produkt (6,423 stimulante metu) hervortritt, um letztmals auf der Handlungsebene des Bell. civ. eine vergebliche Suche nach Zukunftswissen durch Mantik ins Werk zu setzen $^{91}$. Wenn wir uns an den Spekulationen über die Motive des Dichters bei der Wahl dieser Figur beteiligen wollen, so mögen die Nachrichten von einem Interesse der historischen Person an magischen Praktiken zwar einigen Lesern einleuchten, sie stehen aber sicherlich hinter dem überzeugenden Faktum zurück, daß Sextus wegen des Informationsmangels und seiner schattenhaften Existenz in der schriftlichen Tradition dem Dichter besonders geeignet erschienen sein dürfte ${ }^{92}$. Er läßt ja Bell. civ. 8,204f. sogar die dem eigenen Erzähler widersprechende Tradition zu Wort kommen, Sextus sei gar nicht in Thessalien, sondern bei Cornelia auf Lesbos gewesen ${ }^{93}$. In seiner Zeichnung des Sextus im sechsten Buch kann der Sprecher daher seinen Ahnungen (praesagia) folgend weitgehend ohne Rücksichten auf bestehende Züge schalten und die Figur gänzlich zu einem Teil des Geschehens machen. Wie sehr Sextus nur für die Ericthoszene konzipiert wird, zeigt der Vergleich mit dem neunten Buch, wo der Sprecher Cornelia ihrem Sohn den Nachfolgeauftrag geben läßt (9,84-97) und dem Brüderpaar Züge vergilischer Kämpferpaare verleiht, die sich dem neuen Führer Cato zugesellen (9,120-166). Sextus bleibt im sechsten Buch eine (der Erictho darin vergleichbare) Funktion des Geschehens, und ist, wie wir sehen werden, aufgrund seiner Genese aus der Angst der Menge keineswegs ein dem Dichter unsympathischer Charakter. 
32 Ein letzter Blick auf die Figuren soll uns $\mathrm{zu}$ den eingangs skizzierten Deutungsdimensionen der figura zurückführen, um darauf $\mathrm{zu}$ verweisen, daß darin einige der vorgeschlagenen, “abstrahierenden” Lektüren der Akteure Rückhalt finden können. Insbesondere am Beispiel der Landschaft haben wir gesehen, daß diese Ereignis, Figur und Erzählung ihrer selbst sein kann. Auf einer viel einfacheren Ebene ist die Überführung eines Flusses oder anderer geographischer Elemente über die vermittelnde Vorstellung einer Gottheit in eine handelnde Gestalt ebenso geläufig wie die, wenn auch seltenere, figurale Darstellung eines genius loci oder einer Fortuna loci ${ }^{4}$. Die Bindung der Erictho an den sie hervorbringenden Landstrich ist also technisch vorbereitet, ohne daß die poetische Komplexität der figura und ihre Beziehung zur Vorstellung der Entzweiung, wie sie am Beispiel des Bürgerkriegs exemplifiziert wird, bereits erschöpfend erklärt wäre. Die Bedingungen ihrer Genese gleichen der Verbildlichung des Abstrakten. Die gestaltlosen Dinge (res caecae) und solche, die dem Urteil der sinnlichen Anschauung entzogen sind, soll eine gewisse Gestaltgebung (conformatio), ein Bild (imago), eine Figur (figura) so bezeichnen, daß wir das, was wir im bloßen Denken kaum erfassen, gleichsam in den Blick nehmen können ${ }^{95}$. Aufgabe der Redner und Dichter ist somit eine doppelte, denn sie müssen zunächst etwas aus dem Konkreten abstrahieren (zum Beispiel die Struktur eines Geschehens, die Kausalität, die Bedeutungen), um diese Abstraktionen dann wiederum in der Vorstellungswelt der Hörer zur Anschauung zu bringen. Gemäß den Beobachtungen zum Bellum civile erscheint Dichtung als ein Verfahren, mit dessen Hilfe die Anschauung selbst als die Wahrheit erscheinen kann, die es zur Kenntnis zu bringen gilt. Poietische Handlungen dienen daher der Schaffung von Instanzen der Anschauung, in denen zum Beispiel Figuren gleichermaßen sich selbst und die ihnen zugrunde liegende Form ihrer Anschauung bedeuten können ${ }^{96}$. Wenn sich das Schaffen von Figuren daher auch als Gestaltgebung von Abstraktionen verstehen läßt, die nach der Definition des Rutilius Lupus zur Prosopopoiie eine eigene Wirklichkeit verleiht ("Denn sie [sc. die Dichter] haben Personen in menschlicher Gestalt hervorgebracht, die in der Wahrheit der Kunst und des Willens Bestand haben [...])" ${ }^{97}$ ), können wir im nächsten Schritt Erictho auf den ersten Teil dieser doppelten Bewegung hin untersuchen, nämlich auf ihre Abstraktion aus dem Konkreten der Literaturgeschichte.

\section{Die Frau auf der Klippe und die verlorene Stimme der Sibylle}

33 In der Figurenkonzeption der Erictho fehlen wichtige Kategorien, die zu ihrer Bestimmung beitragen könnten (Status [Mensch, Dämon, Göttin?], Herkunft, literarische Vergangenheit, Konsistenz, weiteres Geschick). Andererseits ist sie in einem solchen Maß ausgestattet mit Eigenschaften, daß ihre Entzifferung wegen der schieren Zahl der Verweise und deren innerer Widersprüchlichkeit jedes Mal in der Aporie $\mathrm{zu}$ enden scheint ${ }^{98}$. Sie trägt gleichzeitig Züge des dämonischen Caesar, des rigiden Cato, der römischen (vergilischen) Sibylle, des vergilischen Anchises, der Allecto, der Apollopriesterin aus bell. civ. 5 und des Dichters (sowohl als Antagonistin wie als sein Ebenbild) ${ }^{99}$. Hinzu kommt die Verwandtschaft mit Allegorien und Personifikationen der Rache, des Krieges und der Zwietracht ${ }^{100}$. Der Sprecher führt diese unbestimmte Erscheinung derart ein, daß sie dem Leser plötzlich und ohne literarische Ankündigung entgegentritt ${ }^{101}$. Ein Detail sei bereits gesondert vermerkt: 
Erictho tritt nicht im Anschluß an die Schilderung aller Hexen, sozusagen als deren Anführerin auf, sondern im Anschluß an den Katalog der Künste, deren Steigerung zu unerhörten Praktiken ihr Hauptanliegen ist (6,509 inque novos ritus pollutam duxerat artem) ${ }^{102}$. Da auch im Folgetext alle Aufmerksamkeit auf ihrem Tun liegt, können wir ihre Figur als Abstraktion aus allen Künsten, aus einem Katalog von Fähigkeiten, und weniger als Repräsentation einer Menge von Hexen verstehen. Erictho erscheint als die eine, aus allen anderen extrapolierte, als die vollkommene Kunst ${ }^{103}$.

Bevor sich jedoch diese Emergenz aus der Kunst besser beschreiben läßt, müssen wir das Verhältnis (ebenfalls eines der Emergenz) näher betrachten, das Erictho als Figur der Handlungsebene mit der literarischen Tradition verbindet. Die Aufenthaltsorte der Hexe sind in unbestimmten Zwischenbereichen angesiedelt, wie auch das gesamte Land durch seine unwirksame Trennung von Oben und Unten charakterisiert ist ${ }^{104}$. Die Figuren der Bewegung aus einem Unteren nach oben hin bilden das zentrale Element der Figurenkonstruktion. Nächtens, wenn die menschliche Sinneskraft versagt (sc. wenn der Sprecher die Sinneskraft für unwirksam erklärt hat; 6,618f. si nimbus et atrae/ sidera subducunt nubes), steigt Erictho aus den Behausungen der Toten nach oben $(6,619 f$. tunc Thessala nudis/ egreditur bustis). Die räumliche Auffassung bestimmt auch die erste Begegnung von Figuren der Handlungsebene mit Erictho. Sie wird hoch über der poetischen Landschaft auf einem abschüssigen Felsen des Haemus hockend erblickt (6,575 praerupta in caute sedens), einem geographisch unmöglichen Ort, von dem aus sie auf Thrakien, nicht Thessalien schauen würde ${ }^{105}$.
6,573-76
deserta per arva
carpit iter. fidi scelerum suetique ministri
effractos circum tumulos ac busta uagati
conspexere procul praerupta in caute sedentem,
qua iuga deuexus Pharsalica porrigit Haemus.

Das Zusammentreffen der Protagonisten des sechsten Buches konzipiert der Sprecher, der ja beide hat aus unterschiedlichen Untergründen "hervorgehen" lassen, mithilfe verschiedener Fragmente von Begegnungsszenen, die er wie Erictho aus verschiedensten Bereichen hervorholt und zusammensetz ${ }^{106}$. Insofern Erictho aus der Landschaft hervorgeht und auf einer Klippe in dieser Landschaft zum ersten Mal erblickt wird, besetzt sie die steilaufragenden Felsen, auf denen sich sonst in der Literatur Verliebte, Verzweifelte und Rasende tummeln. Während diese von Affekten und furor widerwillig getrieben wurden, befindet sich Erictho dort in freiwilligem Verzicht auf die Gemeinschaft ${ }^{107}$. Eine bedeutsame Umkehrung des Szenentypus liegt auch in der Blickrichtung, insofern die Vorgänger(innen) sich vielleicht erhoffen, in der Ferne Linderung zu sehen, aber nicht gesehen werden, Erictho aber Objekt der Blicke derjenigen ist, die Heilung von einem Affekt (der Angst) suchen ${ }^{108}$. Während der Ausgangstypus aus der Vorstellung entsteht, daß die Gemeinschaft gesund, der Vereinzelte aber vom furor getrieben ist, sind die Grenzen im Falle der Erictho, die in monadischer Obsession mit ihren Künsten beschäftigt ist (6,677-79), und der aus der Menge hervorgetretenen scelerum fidi ministri um Sextus weniger eindeutig, was sich als Hinweis auf die im letzten Kapitel zu erläuternde, spezifische Verbindung Ericthos mit dem Römischen verstehen läßt ${ }^{109}$.

In der Aufarbeitung der Tradition von Begegnungsszenen sehen wir den Dichter wiederum damit beschäftigt, Amalgame und Kontaminationen in der Weise der poietischen Künste Ericthos herzustellen. Um Aeneas einzubinden, ruft er nicht zuerst 
den vergilischen, sondern dessen ovidische Erscheinung auf, beginnend mit der Kennzeichnung der Diener als fidi und der Junktur carpit iter (Bell. civ. 6,574) ${ }^{110}$.

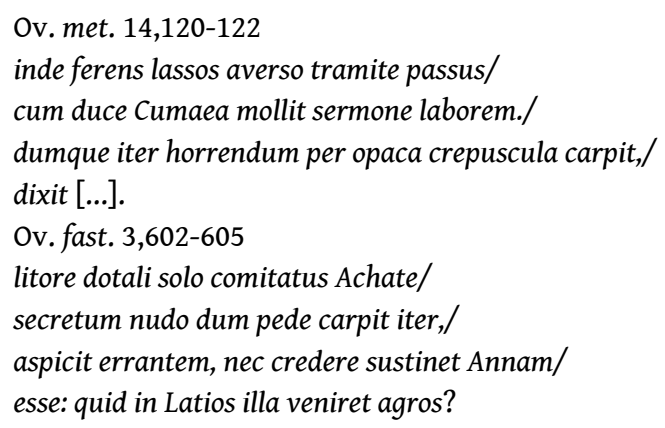

In Fasten und Metamorphosen wählt Ovid für Aeneas" Bewegung durch die Unterwelt bzw. am italischen Strand die ihm vertraute Junktur iter carpere ${ }^{111}$ und arbeitet in die Begegnung mit Anna die für die Unterwelt geprägten Elemente der Abgelegenheit (fast. 3,603 secretum), Verletzbarkeit (nudo pede) und ungläubigen Staunens ein (aspicit, nec credere sustinet). Begleitet allein von Achates (comitatus) oder unter Führung der Sibylle (met. 14,112 me duce. 121 duce Cumeae) wird der Romgründer mit der Forterzählung seiner von Vergil abgeschlossenen Vergangenheit konfrontiert, jeweils im Schicksal von Frauen (Anna, Sibylle). Daß die Begegnung des ovidischen Aeneas mit Anna nicht zu einer Begegnung mit einer Rächerin aus der Vergangenheit gerät, verhindert Dido selbst in ihrer nächtlichen Erscheinung ${ }^{112}$. In allen Szenen wird konstant der Gegensatz zwischen dem Einzelnen und der Gemeinschaft bearbeitet, so daß in ihrer Vereinzelung Sextus, Erictho, Dido, Aeneas, Achates und die Sibylle fähig zur wahnsinnigen visio, zugleich (und davon bedingt) aber auch in unwiderruflicher Entfernung zur Gemeinschaft erscheinen (solus, sola, incomitata) ${ }^{113}$.

Der Dichter des Bellum civile hat offenbar die ovidische Ambivalenz der Darstellung dessen vergilischer Vorlage vorgezogen. Aeneas hat in der Unterwelt deren Gesetze gelernt (didicit), von neu(artig)en Kriegen erfahren (novis bellis) und taucht, mit diesem neuen Wissen versehen, wieder an der Oberwelt auf (emergit) ${ }^{114}$. Es ist verlockend, in diesem expliziten Hinweis auf emergere, das den Gang der Figur, aber auch die Veränderungen des Aeneas von einer vergilischen zur ovidischen Figur meint, einen Hinweis auf die Berechtigung unserer terminologischen Überlegungen zu sehen, zumal Ovid bereits die Ordnungsmuster, die Vergils Unterweltgang prägen (Ober-/ Unterwelt, Führung, Wahrheitsschau etc.), zur Auflösung bringt und seinen Helden aus der literarischen Vergangenheit verändert emporsteigen läßt ${ }^{115}$. Im Bellum civile ist die möglicherweise befreiende Wirkung einer Katabasis zusammen mit der Trennung von Ober- und Unterwelt aufgegeben, so daß der gezeichnete poetische Raum eine Nekyia schlicht nicht zuläßt. Wie im Falle der Götterebene findet also auch kein Ersatz oder eine Umkehr des Ganges in die Unterwelt statt, sondern dieser erscheint (kommt hervor) in einer Gestalt (figura), die den räumlichen Gegebenheiten angemessen ist.

Wenn es sich auch bei den Beziehungen, die Dichter zwischen ihren Texten herstellen, um Phänomene handelt, die wir mit dem Begriff der Emergenz fassen können, so ergibt sich für Erictho eine weitere, poetologisch bedeutsame Dimension, die sie als Emergenz literarischer Diskussionen erscheinen läßt. Ein emergentes Phänomen besitzt auch Qualitäten, die im zugrundeliegenden System enthalten sind, in ihrer neuen Kombination aber neue Eigenschaften generieren, die nicht aus der Summe der vorher bekannten Teile absehbar waren. ${ }^{116}$ Es sind weniger die poetologischen Signalworte, die das zugrundeliegende System kennzeichnen, aus dem Erictho hervorgeht (simulacra, 
imago, figurae, novus), als vielmehr die Figur der ovidischen Sibylle. ${ }^{117}$ Dem unwissenden (und auch nach seiner Reise offenbar nicht belehrten) ovidischen Aeneas berichtet die Sibylle nicht von zukünftigen Geschicken Roms (oder einer Partei im Bürgerkrieg), sondern von ihrem eigenen Schicksal, das sie in einem völligen Schwinden ihres Körpers enden sieht (Ov. met. 14,147-149). Bleiben wird von ihr einzig die Stimme.

Ov. met. 14, $152 \mathrm{f}$.

usque adeo mutata ferar nullique videnda,/

voce tamen noscar, vocem mihi fata relinquent."

Im Bellum civile aber ist selbst die Stimme der Sibylle verschwunden. Ihre Erscheinungsweise als delphische Priesterin hat dieses Schicksal im fünften Buch des Bellum civile erlebt. Insofern Erictho nun ihre neue figura ist, diejenige, die künden soll vom Fortgang der römischen Sache, ist deren Scheitern an der Aufgabe, dem Dichter auf der Ebene der dargestellten Figuren eine Stimme zu geben, sogar explizit und beinahe rituell vollzogen. Erictho sucht nämlich vergeblich bei den Toten eine kündende Stimme (6,631 uocem defuncto in corpore quaerit) und wählt ihre Leiche mit wissenschaftlichem Scharfsinn nach der Fülle seiner Stimme aus, die nur aus frischer Lunge stammen kann $(6,622 \text { [ut] plena voce sonent })^{118}$. Während der Versuch mit der Totenstimme scheitert, ist Erictho selbst auch als mögliche Nachfolgerin für die verschwundene Stimme der römischen Sibylle ungeeignet. Der Sprecher vermerkt nämlich, daß der Hexengesang seine Schauerlichkeit aus der Tatsache gewinnt, daß in ihm alle Stimmen und Laute der Lebewesen vereint sind ${ }^{119}$. Der Dichter findet also keine Stimme bei den Akteuren, der er seine visio anvertrauen könnte, umgekehrt ist Erictho die notwendige Folge der literarischen Position, die die Figur der Sibylle bei Ovid erreicht hatte. Erictho kommt aus dem literarischen System an der Stelle der Sibylle hervor, markiert aber darin gerade deren endgültiges Verschwinden. Einfachen Akteuren, so scheint es, können Dichter ihre Einsicht nicht mehr anvertrauen.

\section{Erictho als Ekstase Roms und die Figur der Entzweiung}

41 Das Problem, das sich aus dem Ausfall der Stimmen ergibt, prägt in gleicher Weise die spezifischen Darstellungsformen des Bellum civile, wie wir es im Falle der Akteure, der Sprecherfigur, der Landschaft und der Verhältnisse des Abstrakten zum Konkreten in Ansätzen beschrieben haben. ${ }^{120}$ Zunächst wenden wir uns nun, um zu einer deutlicheren Fassung der besonderen Funktion Ericthos im Kontext des gesamten Textes zu gelangen, der Frage zu, was im Werk nach dem Verlust der deutenden Stimmen an die Stelle der verbalen Äußerung von Einsicht (Wahrheit?) tritt. Als erstes ist eine für das Werk zentrale, spezifische Tätigkeit zu nennen: die Zerlegung.

Die Ankündigung einer poetischen Anatomie bietet das Prooem (Bell. civ. 1,3 in sua victrici conversum viscera dextra), worin (wie in 1,1 plus quam civilia) auch der Überstieg von der bloß sekundären, kommentierenden Behandlung eines vorgegebenen Stoffes, hier des Bürgerkrieges, zu einer ästhetisch fundierten Analyse der Entzweiung zu sehen ist. Wir können darin die Ankündigung eines Verfahrens erkennen, einer Anatomie des römischen Körpers, in der aber die physische bzw. materiale Ebene der abstrakten, gedanklichen Ebene als Möglichkeit der Veranschaulichung zugesellt ist, nicht umgekehrt das Physische sekundär mit Geistigem erfüllt würde. Das, was sich unserer Auffassung nach als gedankliches Fundament des Bellum civile ausmachen 
läßt, ist die Figur der Entzweiung, die in der Ankündigung der Anatomie bereits enthalten und im gesamten Text, vor allem in den Zerlegungen, einer Prüfung, einer Analyse und Deutung unterzogen wird. Da es sich vor allem um das Häßliche handelt, an dem der Dichter seine Prüfung vollzieht, sei auf die ästhetische Würdigung verwiesen, die Rosenkranz $(1853 / 1990,242)$ im Hinblick auf das Scheußliche formuliert hat: "Es befriedigt uns nicht, wie das vollkommen Schöne, durch absolute Versöhnung in dem Innersten unseres Wesens, sondern wühlt vielmehr aus den Tiefen desselben die äußerste Entzweiung hervor." Unsere These könnten wir dahingehend erweitern, daß wir das "Hervorwühlen der Entzweiung" als Hinweis sowohl auf die Tätigkeit des Dichters verstehen wie auf die Umkehrung des üblichen Verhältnisses: Nicht folgt der Harmonie die Entzweiung, sondern die Entzweiung stellt den Grund dar, der überbaut, nicht aber verlassen werden kann.

Von Beginn an arbeitet der Sprecher in der Rede vom römischen Körper mit Vorstellungen der Trennung und Teilung: Kopf (caput) ${ }^{121}$, Eingeweide (viscera) und mens bzw. animus sind isoliert den Mißhandlungen ausgesetzt, sowohl metaphorisch, metonymisch als auch konkret bezogen bleiben die Teile voneinander geschiedene. ${ }^{122}$ Der römische Körper als Exerzierplatz einer radikalen Anatomie, die in der Sektion des Textes auf seine möglichen Aussagen zur Figur der Entzweiung hin vollzogen wird, ist sowohl (in konkretisierender Einholung der [ästhetisch unbefriedigenden] alten Körpermetapher) als Gesamtes wie in seiner repräsentierten Form des Einzelkörpers römischer Bürger von den oben bereits zitierten Erinnerungen des alten Mannes an präsent $^{123}$. Das Bild vom Körper des Vaterlandes, aus den adhortativen Euphemismen politischer Rede transponiert, ist in der Konkretheit der einzelnen toten Soldaten gefaßt: Caesar befiehlt die Verstümmelung in medizinischer Kenntnis der Blutbahnen und Eingeweide des Reiches, er schreitet durch die inneren Organe des Vaterlandes und bestätigt die Rede Catos, der dem toten Körper Roms in einem Leichenzug folgen will, um sich des endgültigen Todes sicher zu sein ${ }^{124}$. Verstümmelungen einzelner und des ganzen Körpers stehen in so enger wechselseitiger Verbindung, daß eine einzelne metaphorische Übertragung keiner Markierungen bedarf ${ }^{125}$.

In der analytischen Ordnung der Zerstückelung von Leichen (oder der Lebenden in den Sterbeszenen z.B. des dritten Buches) treten die Leidenschaften des Sprechers hinter die anatomischen Obsessionen der Beteiligten zurück ${ }^{126}$. Ericthos Praktiken der Zerlegung sind auf die Fundorte abgestimmt (Steingräber, Galgen, Kreuz, nackte Erde), und ihre wissenschaftliche Präzision (scrutata) wird von der Textorganisation minutiös mitvollzogen. Sowohl in der Reihenfolge und Ordnung ihrer Handlungen, wie in der Konzentration darauf, das Antlitz der Toten zu zerstören, führt Erictho aber nur die Praktiken fort, die vor ihr die anonymen Römer, und damit keine individuierbaren Ausnahmen, sondern das Volk in seinen Teilen, in einem früheren Bürgerkrieg angewendet haben ${ }^{127}$.

6,540-46

tunc omnis avide desaevit in artus 540

inmergitque manus oculis gaudetque gelatos

effodisse orbes et siccae pallida rodit

excrementa manus. laqueum nodosque nocentis

ore suo rupit, pendentia corpora carpsit

abrasitque cruces percussaque uiscera nimbis

volsit et incoctas admisso sole medullas.

2,181-185

Avolsae cecidere manus, exsectaque lingua 
palpitat et muto vacuum ferit aera motu.

Hic aures, alius spiramina naris aduncae

amputat; ille cavis evolvit sedibus orbes

ultimaque effodit spectatis lumina membris.

Im gierigen Zerteilen der Glieder eilt Erictho Caesar voran, in der Zerstörung des Antlitzes ist sie Nachahmerin der anonymen Römer, die besondere Aufmerksamkeit ruht auf dem Entnehmen der Augen und der skrupulösen Erforschung der leeren Höhlen (immergere manus oculis, gelatos effodisse orbes - cavis evolvere sedibus orbes, ultima lumina effodere) ${ }^{128}$. Gegenüber den Tieren zeichnen sich die anonymen Römer, ihr (historisch späterer) Führer Caesar und Erictho dadurch aus, daß sie keiner Sättigung erliegen und ihnen der Überfluß an Leichen keinen Anlaß gibt, auf den Vorstoß in das Innerste (viscera) zu verzichten ${ }^{129}$. Die Widerstände des sich als Einheit behauptenden Körpers werden in hartnäckigem Ringen überwunden (6,547-549), um die Sektion der viscera zu vollziehen und die Zerlegung des Antlitzes zu vollenden ${ }^{130}$. Es ist naheliegend, wie im oben beschriebenen Fall der Schlachtfelder von Pharsalos oder den gescheiterten Orakelbefragungen von einer poetischen Identifikation auszugehen, die wiederum stärker die Handlung an sich und ihre Präsenz als die chronologische Verteilung auf zeitlich frühere oder spätere Akteure im Blick hat.

Ericthos Domäne ist nun aber nicht so sehr der Tod als vielmehr das Ekelhafte, das im Zerstückeln der Leichen und ihrem Kannibalismus seine Existenz erhält ${ }^{131}$. Im Manipulieren der Leichen steckt eine Figur des Selbstverhaltens, die Erictho mit anderen Akteuren auf der Geschehensebene gleichermaßen manifestiert. Die Handlungen sind zur Vollkommenheit gebracht und zeigen darin ihre habituelle Qualität, denn die Zerstückelung scheint ein dauerhafter Teil des Römischen geworden $\mathrm{zu} \operatorname{sein}^{132}$. Was Erictho von den übrigen Erscheinungsweisen des Ekelhaften unterscheidet, ist die Tatsache, daß sie mit dem Grund des Ekelhaften, der Entzweiung, wesenseins gedacht ist. Anders dient zum Beispiel die Zerstückelung der Einzelkörper eines Baebius, Antonius oder der Crassi (2,119-125; viscera, membra, lacer, pendentia ora, truncus, tribunicius tabes) noch dem Anliegen, die Entzweiung im Inneren des Gemeinwesens zu illustrieren, in dem sich viele (innumerae manus, corona, miles, Fimbria) gegen die Teile des eigenen Ganzen wenden ${ }^{133}$. Hier sind vielleicht symbolische, abbildende und auf der Relation von Subjekten zu Objekten beruhende Vorstellungen greifbar, im Fall der Erictho ist dies nicht möglich, weil sie aus diesen einzelnen Ereignissen erst hervorkommt, im Sinne unseres Begriffes ein emergentes Phänomen ist.

Erictho kommt aus dem Text hervor ("emergit"), wird aber gerade darin kenntlich, daß sie bedingungslos in die innersten Körperbereiche eintauchen will (immergit) ${ }^{134}$. Sie übt eine ästhetischer Attraktion aus, die vor allem auf dieser Doppelbewegung beruht, indem in ihr das Abstoßende kulminiert und das Abstrakte zugleich konkretisiert wird. Die Überforderung des Denkens, die die Selbstbezüglichkeit der Zerstörung des eigenen Inneren hervorbringt, wird in die Anziehungskraft der Erictho auf der einen, ihre obsessive Hinwendung zu den Eingeweiden andererseits entfaltet. Der Bürgerkrieg als rein stoffliches Element ist ungeeignet dafür, solche Figuren hervorzubringen, denn in ihm könnten nur mit (z.B. allegorischen) Ersetzungsverfahren ästhetische Momente verankert werden. Erictho hingegen ist eine Verdichtung des Textes (figura), in dem alles Material der sprachlichen Erfassung gleichzeitiger Anziehung und Abstoßung sowie eine grundgebende Figur wie die der Entzweiung allein faßbar werden ${ }^{135}$. 

Akteurin, die mit Zerstörung beschäftigt ist. Die Sprecherfigur erkennt in ihr, genauso wie in den übrigen figurae des Häßlichen, Ekelhaften oder Schrecklichen im Bellum civile, die Figur der Entzweiung als eine unterhalb der Geschehensebene angesiedelte Größe, die einzig aus dem konkreten Text in seiner konkreten Gestalt hervorgehen $k^{k a n n}{ }^{136}$. Die ästhetische Attraktion der Erictho steigert sich noch durch ihre Wendung zum literarischen Kannibalismus, wie er sich im Übermaß ihrer Bezüge zu Subtexten äußert. Erictho perfektioniert die Zerlegung des Inneren zur poetischen Kunst und setzt die Anatomie der Nachahmung durch die Einswerdung mit dem Gegenstand in den Kannibalismus der Poesie um (die Vorbildpassagen dienen als Mahl) ${ }^{137}$. Die Nekroskopie der Erictho verläuft im Interesse einer Nekropsie durch den Dichter, dessen mögliche Motivation, im Sinne der modernen Obduktion, den Todesursachen näherzukommen, von der kannibalistischen Obsession Ericthos verdeckt wird. Der Kannibalismus Ericthos ist allerdings kein Symbol für die römische Selbstzerstörung, denn erstens würde das Symbolverhältnis die alte Hierarchie wieder einsetzen, und zweitens fehlt dem Kannibalischen noch das Moment der Selbstbezüglichkeit, das Entzweiung in ihrer Radikalität auszeichnet. Daß die Selbstbezüglichkeit vornehmlich durch die Beziehung eingebracht wird, die der Sprecher zwischen der Geschehensebene und der Innenseite des römischen Körpers herstellt, soll uns nun beschäftigen.

fern Erictho weitgehend vergangenheitslos ist, kann der Sprecher sie mit der römischen Vergangenheit ausstatten. Ihre Praktiken der Zerlegung übernimmt sie aus dieser Vergangenheit und wiederholt sie im Sinne des Rituals, das aber die ungesühnten Verbrechen nicht abzuwaschen, sondern tatsächlich zu wiederholen geeignet is $\mathrm{t}^{138}$. Unsere Überlegungen $\mathrm{zu}$ Thessalien könnten in dem Sinne hier aufgenommen werden, daß dieses (wie Erictho) die Folgen der ungesühnten Verbrechen bereits zur Anschauung gebracht hat und auch daher den geeigneten Grund abgab, aus dem die römische Figur der Erictho entwickelt werden konnte ${ }^{139}$. Wie sehr das Römische und Erictho bereits in der oben skizzierten Begegnung mit Sextus verbunden werden, zeigt uns ein Detail der Szenenkomposition ${ }^{140}$. In Ovids (?) epist. 21 (Cydippe an Acontius) schildert die Sprecherin ihre Fahrt nach Delos, die zur Begegnung mit dem späteren Geliebten bei den Festlichkeiten führt: die Reise, die Riten nach Ankunft, das Ersehnen des Ortes, sein Ruf, das Umherirren in fremder Umgebung, schließlich das Zusammentreffen ${ }^{141}$. Die Parallelen verweisen auf einen erotischen Subtext zur Begegnung von Sextus und Erictho, aber auch zum Aufgehen der Erictho im Lager der Pompeianer, in dem ihre sichtbare Ekstase - das Heraustreten aus dem Textganzen - ein Ende findet und wo sie wieder in das Textsubstrat eingeht. Auch die vor Liebe rasende Dido Vergils dient in dieser Szene dem Dichter als Materialfundus ${ }^{142}$.

Von begehrendem furor getrieben, verliert Dido allein in der Einöde die Fähigkeit zu differenzierender Wahrnehmung. Insofern Sextus ebenso vom vanus furor getrieben in die Einöde Thessaliens zieht und dort, wie gesehen, eine Frauenfigur auf der Klippe entdeckt, könnte auch sein Sehen (videre) dasjenige Didos sein, die nach den Worten des Servius von Vergil klug als Sehende beschrieben wird, obwohl sie lediglich glaubt, etwas zu sehen (putat se videre) ${ }^{143}$. Nunmehr wäre Sextus derjenige, der im Wahn zu sehen glaubt, nämlich die Erscheinung des Römischen als einer Figur der Entzweiung, und wir haben bereits gesehen, daß die Ambivalenz des Sehenkönnens im Bellum civile von großem

Dictynna, 3 | 2006 
poetischen Interesse ist ${ }^{144}$. Wichtiger ist aber nun, daß den Protagonisten darüber hinaus auch das erotische Begehren zugesprochen wird.

6,826-30

Accensa iuvenem positum strue liquit Erictho

tandem passa mori, Sextoque ad castra parentis

it comes; et caelo lucis ducente colorem,

dum ferrent tutos intra tentoria gressus,

iussa tenere diem densas nox praestitit umbras.

51 In abrupter, nüchterner Kürze bricht der Sprecher die mit so großem Aufwand vorbereitete Nekromantie-Szene $a b$ und läßt (zunächst) alle drei Protagonisten gleichermaßen aus dem "gespenstischen" ${ }^{145}$ Konstrukt Thessaliens wie aus der historischen Ereignisebene in den Textuntergrund zurückkehren. Der Verzicht auf die konventionelle Beschreibung einer Publikumsreaktion unterstreicht die Aussageleere der Totenrede, nach einer letzten Retardation (der Tote muß selbst den Scheiterhaufen besteigen) wird noch einmal die Nacht verlängert und Erictho begleitet Sextus zurück ins Lager ${ }^{146}$ - it comes. Anders als die gerade vernommene Weissagung dem Aeneas und Achates ist den beiden Figuren bei Lucan die (leere) Rede des Toten keine Überlegung wert $^{147}$, stattdessen wird eine verstörende Vertrautheit zwischen Sextus und der Hexe durch Parallelen zur vergilischen Paarung Aeneas/ Achates (fidus it comes) und $\mathrm{zu}$ Lucans Paarung Cornelia/ Pompeius (fida comes) vorgestell $t^{148}$. Erictho ersetzt die treuen Diener (fidi), die Sextus zu ihr begleitet hatten, und verschwindet folgerichtig gemeinsam mit dem späteren Erben des Magnus Pompeius in dessen Lager.

Das Aufgehen der Erictho im Lager der Römer kann nach der aus der früheren Übertragung römischer Verhaltensweisen extrapolierten engen Verbindung zu Sextus als Rückwendung in den Text verstanden werden, in dem uns mehrfach die Auseinandersetzung mit dem römischen Gemeinwesen als von der Entzweiung erfaßtem Körper begegnet war, dessen Innenseite, die innere figura (Roms Verfaßtheit), zwar notwendig gedacht ist, bisher aber nicht explizit zur Sprache kam. Die Äußerung der inneren figura aber dürfte in Analogie zu den bisher gesehenen poetischen Verfahren ebenfalls in Verbindung zur Geschehensebene gebracht sein. Es sind die Patria im ersten und ihre Neufigurierung als Erictho im sechsten Buch. Nach der Abtrennung der Glieder vom Haupt in der Wendung zum Bürgerkrieg erscheint die verzweifelte Patria. Eine äußerlich zerstörte Frauengestalt, von geisterhaftem Wesen, sucht Caesar nächtens aufzuhalten ${ }^{149}$.

1,186-89

ingens uisa duci patriae trepidantis imago

clara per obscuram uoltu maestissima noctem

turrigero canos effundens uertice crines

caesarie lacera nudisque adstare lacertis

Die Erscheinung der inneren Gestalt als eines Getrennten ist möglich geworden durch die oben beschriebene Teilung des Organismus (caput, viscera) ${ }^{150}$. Der Hell-DunkelKontrast im Antlitz der Patria gegenüber dem umgebenden Dunkel (clara per obscuram) wiederholt sich in der Konfrontation zwischen Unter- und Oberwelt in Ericthos Gesicht ${ }^{151}$. Innerhalb vergleichbarer Szenen agieren die von Angst erfüllte Patria und die Erictho als Figur der Entzweiung, die bereits in der Angst der Patria präsent war, mehr noch, dieser bereits zugunde lag.

Es ist nicht unwahrscheinlich, daß Leser diese Formen der Transformation oder Erscheinung nicht wesentlich verschieden von der Art wahrnahmen, in der sie z.B. der 
"Seelenwanderung" des Pompeius in Bell. civ. $8 / 9$ begegneten ${ }^{152}$. Weil zudem die Figur der Entzweiung in der Spaltung des römischen Körpers schon auf der Geschehensebene des Bellum civile konkretisiert ist, kann der Sprecher Erictho als dessen inneres, "dämonisches" Prinzip präsentieren und diesem nach der begonnenen Zerrüttung der Patria im ersten Buch im sechsten Buch eine "gespenstische" figura zuteilen ${ }^{153}$. Rom ist die zentrale Größe auf der Geschehensebene, und ihre Metamorphosen, ihre verschiedenen figurae, zu denen Erictho zu zählen ist - die Figur der Entzweiung ist in der poetischen Wahrnehmung wesensgleich mit Rom geworden - dürften als Überlebensversuche einer bis zur Unkenntlichkeit verstümmelten figura verstanden werden können, einer figura, die selbst die Verstümmelung veräußert ${ }^{154}$. Wenn wir also eine letzte Spezifizierung unserer Termini versuchen wollen, so können wir Erictho als Ekstase Roms oder eine von deren figurae verstehen, als eine Erscheinungsweise, in der wiederum die Figur der Entzweiung, verstanden als thematisches Fundament des Werkes und zugleich Gegenstand einer poetischen Analyse, die sich dem Phänomen nicht über die Wissensordnungen etwa der Historiographie oder der Naturwissenschaft nähern will, in der diese Figur der Entzweiung also vom Sprecher als identisch mit dem Wesen Roms verstanden wird ${ }^{155}$.

Eine abschließende Bemerkung soll nochmals einen Bogen zur eingangs gestellten Frage nach dem Verhältnis eines Textes zu seinem Gegenstand schlagen. Die vorgeschlagene Lektüre des Bellum civile setzte nicht bei den politischen oder moralischen Implikationen des Textes an, sondern bei einem thematischen Prinzip, das wir in der Figur der Entzweiung gesehen haben. Ein solches Prinzip wird mithilfe von Stoffen, etwa des Historischen, expliziert, das heißt ästhetisch analysiert. Das Bellum civile ist in keiner Weise ein Kommentar zum Bürgerkrieg, geschweige denn ein moralischer Kommentar des Verfassers zur Welt oder ein Ausdruck seiner Affekte gegenüber Zeitgenossen oder Protagonisten der Republik ${ }^{156}$. Was sich mit den vorgestellten Begriffen der Emergenz und der Ekstase zudem verbinden läßt, ist die Vorstellung eines topologischen Textmodells, das keine Hierarchie zwischen Gegenstand und literarischer Gestaltung behauptet und im Bild eines Reliefs auch die Verschiebungen zwischen Abstrakta und Konkreta beschreiben kann, die bei den Gegenstandsmodellen ausgeblendet bleiben. Mit dem Begriff der Emergenz ist also ein Teil eines umfassenderen Modells von Literatur (und den geschichtlichen Verhältnissen literarischer Werke zueinander) skizziert worden, dessen Umrisse noch zu entwerfen sind.

\section{BIBLIOGRAPHIE}

Ahl, Frederick: Apollo: Cult and Prophesy in Ovid, Lucan and Statius, in: Apollo: Origins and Influences, hrsg. v. J. Solomon, Tucson 1994. 113-134.

Ahl, Frederick: Minor Characters, in: Lucan. An Introduction, Ithaca 1976. 121-149.

Ambühl, Annemarie: Thebanos imitata rogos (BC 1,552)-Lucans Bellum Civile und die Tragödien aus dem thebanischen Sagenkreis, in: C. Walde (2005) 261-294. 
Badalì, Renato: Unlukanisches, in: Interpretare Lucano, hrsg. v. P. Esposito/L. Nicastri, Neapel 1999. 255-261.

Baldini Moscadi, Loretta: Osservazioni sull"episodio magico del VI libro della Farsaglia di Lucano, in: SIFC 48 (1976) 140-199.

Bartsch, Shadi: Ideology in Cold Blood. A Reading of Lucan"s Civil War, Cambridge 1997.

Bonner, Stanley F.: Lucan and the Declamation Schools, in: AJPh 87 (1966) 257-289.

Brena, Fabrizio: Osservazioni al libro IX del bellum civile, in: Interpretare Lucano, hrsg. v. P. Esposito/ L. Nicastri, Neapel 1999. 275-301.

Burck, E./Rutz, W.: Die "Pharsalia" Lucans, in: Das römische Epos, hrsg. v. E. Burck, Darmstadt 1979, 154-199.

Danese, Roberto M.: L"anticosmo di Eritto e il capovolgimento dell"inferno virgiliano. Lucano, Phars. 6, 333 sgg., in: Atti della Accademia Nazionale dei Lincei. Memorie della classe di Scienze morali, storiche e filologiche. Rom 1992. 197-255.

Dinter, Martin: Lucan"s Epic Body, in: Walde (2005) 295-312.

Fantham, Elaine: Religio...dira loci: Two Passages in Lucan de Bello Civili 3 and their Relation to Virgil"s Rome and Latium, in: MD 37 (1996) 137-153.

Finiello, Concetta: Der Bürgerkrieg: Reine Männersache? Keine Männersache! Erictho und die Frauengestalten im Bellum Civile Lucans, in: Walde (2005) 155-185.

Gauly, Bardo M.: Senecas Naturales Quaestiones. Naturphilosophie für die römische Kaiserzeit, München 2004 (= Zetemata Bd. 122).

Glaesser, Roland: Verbrechen und Verblendung. Untersuchung zum Furor-Begriff bei Lucan mit Berücksichtigung der Tragödien Senecas, Frankfurt 1984 (= Studien zur klassischen Philologie Bd. 17).

Görler, Woldemar: Caesars Rubikon-Übergang in der Darstellung Lucans, in: Studien zum antiken Epos 72 (1976) 291-308.

Green, C. M. C.: Stimulos dedit Aemula virtus: Lucan and Homer reconsidered, in: Phoenix 45 (1991) 230-254.

Hardie, Philip: The epic successors of Virgil. A study in the dynamics of a tradition, Cambridge 1993.

Hardie, Philip: The Cambridge Companion to Ovid, Cambridge 2002.

Harrison, S. J. (ed.): Texts, Ideas and the Classics. Scholarship, Theory and Classical Literature, Oxford 2001.

Henderson, John: Lucan/The word at war, in: Ramus 16 (1987) 122-164.

Hömke, Nicola: Ordnung im Chaos. Macht und Ohnmacht in Lucans Erichtho-Episode, in: Festschrift H. Görgemanns, hrsg. v. M. Baumbach/H. Köhler/A. M. Ritter, Heidelberg 1998. 119-137.

Holmes, Nigel: Nero and Caesar: Lucan 1.33-66, in: CPh 94 (1999) 75-81.

Hunink, Vincent: Sleep and death (Lucan 9, 818), in: MD 42 (1999) 211-213.

Johnson, Walter R.: Momentary monsters. Lucan and his heroes, Ithaca 1987 (= Cornell Studies in Classical Philology Vol. 47).

Korenjak, Martin: Die Ericthoszene in Lukans Pharsalia. Einleitung, Text, Übersetzung, Kommentar, Bern/ Frankfurt 1996 (= Studien zur klassischen Philologie Bd. 101).

Leigh, Matthew: Lucan. Spectacle and Engagement, Oxford 1997. 
Leigh, Matthew: Lucan"s Caesar and the sacred grove. Deforestation and Enlightment in Antiquity, in: Interpretare Lucano, hrsg. v. P. Esposito/L. Nicastri, Neapel 1999. 167-205.

Maes, Yanick: Starting something Huge: Pharsalia I 83-193 and the Virgilian Intertext, in: Walde (2005) $1-25$.

Masters, J.: Poetry and Civil War in Lucan"s Bellum Civile, Cambridge 1992.

Migliorini, Paola: Scienza e terminologia medica nella letteratura latina di età neroniana. Seneca, Lucano, Persio, Petronio. Frankfurt am Main 1997 (= Studien zur klassischen Philologie Bd. 104).

Most, Glenn W.: The Rhetoric of Dismemberment in Neronian Poetry, in: Innovations of Antiquity, hrsg. v. R. J. Hexter, New York 1992. 391-419.

Narducci, Emanuele: Lucano, un" epica contro l"impero. Rom/Bari 2002.

Narducci, Emanuele: Il Tronco di Pompeo. Troia e Roma nella Pharsalia, in: Maia 25 (1973) 317-325.

O"Higgins, Dolores: Lucan as Vates, in: ClAnt 7 (1988) 208-226.

Papaioannou, Sophia: Epic Transformation in the Second Degree: The Decapitation of Medusa in Lucan, BC 9.619-889, in: Walde (2005) 216-236.

Rosenkranz, Karl: Ästhetik des Häßlichen (1853), zit. nach der Ausgabe von D. Kliche, Leipzig 1990.

Rudich, Vasily: Dissidence and Literature under Nero, London/New York 1997.

Schönberger, Otto: Leitmotivisch wiederholte Bilder bei Lucan, in: RhM 103 (1960) 81-90.

Schrempp, Oskar: Prophezeiung und Rückschau in Lucans Bellum civile, Winterthur 1964 (= Diss. Zürich 1964).

Schrijvers, Piet: The "Two Cultures" in Lucan. Some remarks on Lucan"s Pharsalia and ancient sciences of nature, in: Walde (2005) 26-39.

Sklénar, R.: The taste for nothingness. A study of Virtus and related themes in Lucan"s Bellum Civile, Ann Arbor 2003.

Taplin, Oliver (ed.): Literature in the Greek and Roman Worlds. A new perspective, Oxford 2000.

Todorov, Tzvetan: Einführung in die fantastische Literatur, dt. von K. Kersten, Frankfurt 1975.

Walde, Christine (Hrsg.): Lucan im 21. Jahrhundert, Leipzig 2005.

Wheeler, Stephen: Lucan"s Reception of Ovid"s Metamorphoses, in: Arethusa 35 (2002) 361-380.

Wildberger, Jula: Quanta sub nocte iaceret nostra dies (Lucan 9,13f.)- Stoizismen, in: Walde (2005) 56-88.

Worman, Nancy: Infection in the Sentence: The Discourse of Disease in Sophocles" Philoctetes, in: Arethusa 33 (2000) 1-36.

Zwierlein, Otto: Statius, Lucan, Curtius Rufus und das hellenistische Epos, in: RhM 131 (1988) 67-84.

\section{NOTES}

1. Für zahlreiche Anregungen danke ich den Teilnehmern einer Diskussion, die im Anschluß an den Vortrag einiger der hier vorgestellten Überlegungen in Heidelberg stattfand (bes. W. Görler, G. Kloss, M. Möller und J.P. Schwindt).

2. Im Gegensatz zu "Charakter" oder "Held" verweist "Gestalt" noch auf den Ursprung aus einer konstruierenden Tätigkeit [des Verfassers, des Textes]. 
3. Wie Statuen in der Darstellung der Bewegung im Gegensatz zum Stillstehen kunstvoll erscheinen, so sind Redefiguren auf das erkennbare Abweichen vom "Geraden" angewiesen, um ihre Wirkung entfalten zu können (Quint. inst. 2, 13, 11): gratiam et delectationem afferunt figurae quaeque in sensibus quaeque in verbis sunt. Mutant enim aliquid a recto atque hanc prae se virtutem ferunt, quod a consuetudine vulgari recesserunt.

4. Vgl. die Bilder bei Isid. diff. 1, 528 an: figura est, cum impressione formae alicuius imago exprimitur, veluti si in cera ex anulo effigiem sumat aut si figulus in argillam manum vultumque aliquem imprimat et fingendo figuram faciat (s. ThLL VI,1. 722,60-64).

5. Catulls Gebrauch des Wortes bei der (Beginn und Ende einer Vorstellungswelt behauptenden) Kennzeichnung des Gewebes, das in seinem Text erfunden wird, um diesem wiederum seine Stoffe zur Abbildung zu geben, ist entsprechend vielschichtig (vgl. Catull. 64, 50 vestis priscis hominum variata figuris. 265 talibus ... vestis decorata figuris). Maler grenzen entsprechend durch Farbgebung ihre Darstellungen von lebendigen Wesen von der Umgebung ab (vgl. wieder den Rhetoren Rut. Lup. 2, 7 pictor coloribus figuras describit). Die Erscheinungsweisen sind sowohl durch die fließenden Grenzen als auch ihre Momenthaftigkeit gekennzeichnet; figurae werden angenommen und abgelegt, vgl. z.B. Prop. 2, 33, 13 agrestem detraxit ab ore figuram Iuppiter Ioni. Zwei der drei in ThLL VI 724,76-78 genannten Belege für die prägnante Verwendung von figura als "eine feste (körperliche) Gestalt" stammen von Lucan, der an den Momenten ihres Verlustes interessiert ist: Lucan. 8, 710 nulla ... manente figura (vom in den Wellen schwimmenden Körper des Pompeius) und 9, 792 tendit ... cutem pereunte figura ... tumor.

6. Vgl. Quint. inst. 10,1,90 Lucanus ardens et concitatus et sententiis clarissimus et, ut dicam quod sentio, magis oratoribus quam poetis imitandus (es ist nicht, wie manchmal zu lesen, zwischen Dichtung und Geschichtsschreibung abgewogen - der historische Stoff ist konventionelles Gebiet der Epik).

7. Vgl. Cic. de orat. 1,70 finitimus oratori poeta.

8. Die Rede von einer figura des Sprechers ist der antiken Rhetorik zu entnehmen, in der darunter oftmals die Haltung/ Rolle/ Erscheinung verstanden wird, die für eine bestimmte Situation und Aufgabe gewählt ist (bezogen auf den Text fast wie Gedankenstruktur, Redestrategie). Zahlreiche Belege finden sich in ThLL VI,1,731,27-61, darunter: Sen. contr. 1, 1, 15 ille su figur dixit omnia. 1, 2, 20 ille hac figura narravit. 2, 3, 18 ille hac figura declamavit. 4 praef. 7 eandem rem ... aliis totiens figuris, aliis tractationibus dicere poterat.

9. Grundlegend zu den Rollen des Sprechers im Text ist Leigh (1997), bes. Chap. 2 und 3; vgl. Narducci (2002) 88-106.

10. So auch Leigh (1997) z.B. 76 "dramatic appearance of the narrator as a character in his own drama". Anders als Leigh sehe ich jedoch die prägenden Eigenschaften dieser Stimme (ebd. 76 "emotions of detestation of civil war and yearning to defeat Caesar") weniger in ihrer leidenschaftlichen politischen, als vielmehr poetischen Stellungnahme.

11. Neben den expliziten Verweisen auf Zukünftiges (Ankündigungen wie instabat... [s.u. zu 5,825]) sind Übertragungen aus anderen Szenen ein Hinweis auf die divinatorischen Ansprüche der Sprecherfigur (z.B.: Die Warnung, einen Tyrannen nicht vor Erfüllung seines Werkes zu töten, wird im Kerker des Marius [2,81-83] von plötzlich erschienenen, übernatürlichen Wesen in direkter Rede gegeben, in 7,590-595 gibt sie der Sprecher der Figur Brutus; vgl. 2,78 ferrumque manu torpente remisit; 81-83 Fas haec contingere non est/ colla tibi; debet multas hic legibus aevi/ ante suam mortes; vanum depone furorem! und 7,590-595 [der Sprecher an Brutus] quod ferrum, Brute, tenebas? [...] ne rue ... nec ... admoveris ante ... 593 nondum attigit arcem).

12. Im Hinblick auf die Darstellung des furor in der Poesie hat Rosenkranz (1853/ 1990) klar gesehen, daß seiner Bestimmung der Versuch zugrundeliegt, sich durch willkürliche Teilung von der Brüchigkeit des eigenen Fundaments zu befreien (ebd. 247): "Die Poesie muß uns den Wahnsinn als Folge eines ungeheuren Geschicks zeigen, so daß wir in dem zusammenhanglosen Gefasel des Irrsinnigen die Wut der gewaltigen Widersprüche anschauen, denen der Mensch 
erlegen ist" (seiner Folgerung, die Dichtung habe die Unbeschädigtheit der Idee hinter den Widersprüchen zu vertreten, würden wir allerdings nicht [mehr] folgen wollen).

13. Davon unbenommen ist, daß zum Beispiel Emil Staiger und Wolfgang Kayser mit vollem Recht und Gewinn für die verschiedenen Literaturwissenschaften die Grundlagen ihrer Klassifikation und Typisierung von Erzählelementen an antiken Epen entwickelt haben (vgl. z.B. auch Kategorien wie Breite, Kausalitätsverzicht, parataktische Komposition, Ornamente und Retardation). Allerdings müssen wir heute davon ausgehen, daß die antiken Dichter keineswegs eine Art "naturgegebener" Erzählweise zu erfüllen im Sinn hatten, denn seit dem 1. Jahrhundert v. Chr. darf für Rom als gesichert gelten, daß mit der Reflexion auf die Kategorien eine Problematisierung ihrer Zuverlässigkeit in den Werken selbst einher geht.

14. Das Problem unerklärter Setzung von Hierarchien betrifft weite Bereiche der Literaturanalyse (keineswegs nur in der Klassischen Philologie): Texte werden soweit möglich als sekundäre Bearbeitungen vorgängiger Gegenstände verstanden (Bewußtseinszustände, Geschichte, Moral, Philosophie, Alltagsleben etc.), so daß sie in prinzipielle Abhängigkeit und Rechtfertigungszwänge geraten (z.B.: Historisches ist ursprünglich, seine textliche Erscheinungsweise nur als Modifikation/ Veränderung/ Bearbeitung verständlich; Moralisches ist das Vorgängige, seine Erscheinung im Text ihm untergeordnet als Stellungnahme/ Befragung/ Bewertung zu fassen etc.).

15. Burck/ Rutz (1979).

16. Vgl. z.B. "angstvolle Erwartung und Erinnerung" in ca. fünfhundert Versen am Übergang von Bell. civ. $1 \mathrm{zu} 2$ oder "Bestattung und Totenklage" in ca. fünfhundert Versen am Übergang von Bell. civ. $8 \mathrm{zu} 9$.

17. Vielleicht nicht zufällig endet der Erfolg Lucans einerseits zeitgleich mit dem der Rhetorik, andererseits mit der Homerbegeisterung des 19. Jahrhunderts und Herders Ausruf "Alles muß zur Handlung eilen!” (wo "Eile” allerdings, gemäß dem Homerischen Modell, als vereinbar mit den Retardationen und der sprichwörtlich gewordenen "epischen Breite" des frühgriechischen Epos gedacht ist).

18. Vgl. z.B. Green (1991), zur Homernachfolge im Katalog 6,375-80 Korenjak (1996) 97 ad loc. Für die Schilderungen von Grausamkeit, die manchmal als charakteristisch für Lucan bezeichnet werden, ist die Vorbereitung im hellenistischen Epos greifbar (vgl. Zwierlein [1988], bes. 68-70). $\mathrm{Da}$ auch die frühen römischen Epen Opferszenen als integralen Bestandteil der offiziellen Kulte poetisch entfaltet haben dürften, legt ein Fragment aus dem Bellum Punicum des Naevius nahe, in dem von den atrocia exta die Rede ist, die die Opferdiener darreichen sollten (Nonius 76, 3: atrox: crudum. Naevius Belli Punici III, simul atrocia porricerent exta ministratores [die semantische Engführung [crudum] ist wohl nicht zwingend]).

19. Es ist in der deutschsprachigen Klassischen Philologie noch nicht kommunizierbar, daß eventuell auch Konstellationen auftreten, in denen ein Verfasser seine Sprecherfigur so stark konzipiert, daß sie seinen eigenen Auffassungen diametral entgegensteht. Am Rande bemerkt sei, daß das Problem der ersetzten Götterebene im Bell. civ. (zum Abschied von der Rede eines "Fehlens des Götterapparates" vgl. z.B. Hömke [1998] und Feeney [1991]) wissenschaftlich nur narratologisch oder ästhetisch, nicht aber mit Hinweisen auf ein textlich unfaßbares "Weltbild" des historischen Autors erklärt werden kann. Die Modifikation des narrativen Elementes der Götterebene steht im Einklang mit der Ersetzung intentionaler und kausaler Modelle durch die Emergenz und verbannt die sedativen Elemente einer voluptas des Lesens, die aus dem Wunderbaren im Gegensatz zum Schrecklichen gewonnen werden. Beide gehören dem Bereich der delectatio an, wobei die Zerrbilder des Schrecklichen von der Rhetorik und Poetik (genauso wie bei Lasterkatalogen) lediglich als Gegenteile des jeweils Beschriebenen angesetzt werden. Vgl. zur voluptas, die sich aus dem Gesamtbereich des Übernatürlichen entwickeln läßt z.B. Cic. part. or. 73 über die Personendarstellung: Adhibendaque frequentius etiam illa ornamenta rerum sunt, sive quae admirabilia et nec opinata, sive significata monstris, prodigiis, oraculis, sive quae videbuntur ei 
de quo agimus accidisse divina atque fatalia. Omnis enim exspectatio eius qui audit et admiratio et improvisi exitus habent aliquam in audiendo voluptatem.

20. Ovids Bedeutung für Lucan untersuchen z.B. Wheeler (2002) und Papaioannou (2005).

21. Der letztgenannte Punkt ist dabei nicht gleichzusetzen mit den narratologischen Fragen nach der Dramatisierung eines Geschehens durch Zeitrelationen, insofern in letzteren Zeitstrukturen in erster Linie als Mittel der Textproduktion verhandelt werden.

22. Vgl. zu den Implikationen dieser Kunstgriffe Leigh (1997) z.B. 86 u.ö. (nach O"Higgins [1988] und Masters [1992] bes. 148 über die Verbindungen zwischen Figuren und Sprecher über den Unwillen zu erzählen).

23. Zum Inhalt des Werkabschnittes: Beim ersten Zusammentreffen verweigert Pompeius die von Caesar gesuchte Entscheidung, der daraufhin nach Dyrrhachium zieht (6,1-14). Das Verlassen des hier gegen den Willen überirdischer Mächte bezogene Lager (6,314 deserit averso possessam numine sedem/ Caesar) bildet die Rahmung für die von Caesars erneuter Ungeduld (6,29 avidam belli mentem) initiierte, vergebliche Belagerung, die Schilderung der Hungernöte, verhinderten Schlachten und die Aristie des Scaeva (6,138-262). Mit dem Zug nach Thessalien (6,263-332) wird der Hauptteil des Buches eingeführt, eine Deskription Thessaliens (genannt: "Thessalienexkurs", 6,333-412) eröffnet das Thema, nur unterbrochen von der kurzen Berücksichtigung der Haupthandlung in 6,413-14a (Aufschlagen der Lager). Die unbändige Angst im Lager der Pompeianer treibt Sextus Pompeius zu schwarzer Magie (6,314b-433a), die in Thessalien mit der Hexenbevölkerung besonders präsent ist (6,433b-506). Nach dem Porträt der schrecklichsten von ihnen, Erictho (6,507-69), folgt das Zusammentreffen der beiden (6,570-623), der Vollzug der vereinbarten Nekromantie (6,624-820a), bis in einem abrupten Abbruch der Szene beide zusammen ins Lager zurück (820b-830). Auch das achte Buch verzögert mit schrecklichen Träumen des Pompeius und den Schlachtvorbereitungen die Entscheidung weiter (7,1-213), bis schließlich die Heere sich auf den Weg zur endgültigen Auseinandersetzung machen (7,214ff.).

24. Vgl. bell. civ. 6,1-3 Postquam castra ducespugnae iam mente propinquis/inposuere iugis admotaque comminus arma/ parque suum uidere dei; die Wortstellung mente propinquis $(6,1)$ unterstützt den Eindruck, der Kampf stehe unmittelbar bevor (den Raumbezug auf iugis offenbart erst der Folgevers, zu zeitlichen Implikationen von propinquus s. OLD s.v. propinquus 3).

25. Vgl. die (vorgebliche) Erwartung des Sprechers im Schlußvers des 5. Buches, der die Abschiedsszene zwischen dem zur Schlacht abreisenden Pompeius und seiner Frau mit der Ankündigung des traurigen Wiedersehens beendet $(5,825)$ Instabat miserae, Magnum quae redderet, hora. Die dramatisierende Ankündigung des Sprechers wirkt innertextuell spannungserzeugend (bei einem historischen, dem Leser bekannten Stoff ist Spannung auf der Ereignisebene von untergeordneter Bedeutung), so daß ihre späte Erfüllung in 8,54ff. (nach ca. 1800 Versen) die Aufmerksamkeit zurück auf die merkwürdig affektierte Ungeduld des Sprechers (instabat) lenkt. 26. Untersuchungen hierzu z.B. von Hömke (1998), Danese (1992), Finiello (2005) 155-165.

27. Bell. civ. 8,42-45 maestior, in mediis quam si, Cornelia, campis/ Emathiae stares. Tristes praesagia curas/ exagitant, trepida quatitur formidine somnus/ Thessaliam nox omnis habet. Die Schrecken der Schlacht nehmen in den Albträumen für jeden Soldaten andere Gestalten (figurae) an (vgl. 7,773 sua quemque premit terroris imago; 7,774 [hunc] agitant cadavera), in Caesars Gesichten sind alle Toten präsent (7,776 omnes in Caesare manes). ThLL VI,1, 729, 35f. nennt 7,774 als Beleg für die Bedeutung "Schatten der Toten" von figura und führt dafür nur noch Verg. Aen. 10, 640 an: morte obita qualis famast volitare figuras (allgemein zu Träumen s. auch Walde [2001]). Im Bell. civ. ist die zuverlässige Trennung zwischen Erscheinungen und Ereignissen auf der Handlungsebene ein Problem, das sich dem Sprecher und Leser stellen soll. Das Intensivum agitare und andere Handlungsverben beschreiben die Wirkungen, die die Erscheinungen auf Verhalten und Wirklichkeit der Akteure ausüben. Für das poetische Anliegen des Textes sind die Überschneidungen zwischen Figuren der Handlung und Figuren, die wie Akteure auftreten (sprachliche oder gedankliche), zentral. 
28. Zum Zukunftsbezug vgl. Cic. div. 1,65 is igitur qui ante sagit quam oblata res est, dicitur praesagire, id est futura ante sentire.

29. Die Identität der Zeitstufen wird durchgängig gehalten, indem sich Vision und Erinnerung abwechseln, zur Ausdrucksweise der Präsenz vgl. die Schilderung der Albträume Caesars und seiner Soldaten $(7,764-786)$, in denen das Geschehen fortdauert: 7,764f. somnique furentes/ Thessalicam miseris versant in pectore pugnam.

30. Angstvolle Erwartungen sind Thema des Chorliedes Sen. Thy. 920-969, dessen Behandlung der geistigen Vorahnung ohne Veranlassung durch äußere Zeichen Lucan gekannt haben dürfte, vgl. bes. Thy. 957-960 Mittit luctus signa futuri/ mens ante sui praesaga mali:/ instat nautis fera tempestas,/ cum sine vento tranquilla tument. Ovid met. 11,457f. hatte die Ahnung nicht im Geist selbst angesiedelt und die Deutung des Gesehenen (mit relativierendem veluti) auf die Vorstellung der Figur Alcyone zurückgeführt (qua rursus visa veluti praesaga futuri/ horruit Alcyone).

31. Zum poetischen Begriff der Topothesie zur Bezeichnung eines (vom Geographischen unabhängigen) Entwurfes, der den Ort selbstreferentiell als Vorstellung kenntlich machen soll, vgl. Servius zu Verg. Aen. 1,159 EST IN SECESSV topothesia est, id est fictus secundum poeticam licentiam locus. Die Bedeutung der Landschaftskonstruktion als Untergrund, aus dem das Gesamtgeschehen um Pharsalos hervorgeht, zeigt sich in der Wiederaufnahme der Eröffnung der Thessaliendeskription (6, 333 Thessaliam, qua parte [...]) am Ende des siebten Buches, wo der Sprecher nach der Schlacht das Land selbst anruft (7,847 Thessalia, infelix, ... tellus), dessen wiederholte Rolle in der römischen Geschichte unterstreicht und damit dem sog. "Exkurs" erst hier ein (vorläufiges) Ende bereitet.

32. Korenjak (1996) $92 \mathrm{zu}$ vv. 6,360-80 (u.ö.) spricht von einem "Kosmos im Kleinen”. Zu den geographischen "Unmöglichkeiten" vgl. Korenjak (1996) zu bell. civ. 6,576ff.: Der Haimos liegt 200 km nördlich von Philippi in Makedonien, Pharsalos in Thessalien $200 \mathrm{~km}$ von Philippi entfernt, das makedonische Emathia auf halbem Wege.

33. Diese Unsicherheit des Lesers hinsichtlich des Status des Geschilderten weist einige Verwandtschaft mit dem von Tzvetan Todorov (1975) beschriebenen Element der Ungewißheit als Konstitutivum des Phantastischen auf. Obwohl er dabei vom 19. Jahrhundert und der erfolgten Trennung des wissenschaftlichen vom außer-wissenschaftlichen Vorstellen ausgeht, dürfte die Frage nach dem ontischen Status auch dem Leser Lucans zumindest als Problem erschienen sein (wie stimmen die geographischen Informationen mit denen aus Geschichtswerken, Reiseberichten, Aussagen von Reisenden etc. überein? Wie kann das Land offensichtlich widersprüchliche Eigenschaften gleichzeitig besitzen?).

34. Vgl. den Beginn der Beschreibung in 6,343 Hos inter montes, media qui valle premuntur; dagegen das Emporsteigen des Landes aus dem Wasser in 6,351 eminet. Jeder neue Abschnitt der Beschreibung setzt beim selben Moment des Aufstieges aus dem Sumpf/ Wasser an und suggeriert mehr eine Entwicklung als daß diese vollzogen würde: 6,344 perpetuis quondam latuere paludibus agri; 346 stagnumque inplentibus unus/ crescere cursus erat. 360 Ergo abrupta palus multos discessit in amnes. 381 Ut primum emissis patuerunt amnibus arva.

35. Um Thessalien emporsteigen zu lassen, habe Hercules die Berge gespaltet (6,347f. Postquam discessit Olympo/ Herculea gravis Ossa manu), eine Rehabilitation des von Seneca übergangenen mythischen Musters (Sen. nat. quaest. 6,25,2): si uelis credere, aiunt aliquando Ossam Olympo cohaesisse, deinde terrarum motu recessisse, et fissam unius magnitudinem montis in duas partes. tunc effluxisse Peneon, qui paludes quibus laborabat Thessalia siccauit, abductis in se quae sine exitu stagnauerant aquis (zu den Parallelen zum Lucantext vgl. z.B. die Stellen in der voranstehenden Fußnote). Daß auch Senecas (rationale) Erklärungen in ein umfassenderes Konzept metaphorischer Deutungen der Naturphänomene eingebunden sind, hat Gauly (2004), hier bes. 224-235 erwiesen.

36. Hervorragende Beobachtungen zu den "two cultures" in Lucans Text, speziell den lehrhaften Teilen, bietet Schrijvers (2005) 26-39. 
37. Nur angedeutet werden können Bezüge zu den von T. Todorov (1975) untersuchten Elementen des Fantastischen. Er will eine Gattungsdefinition der fantastischen Prosaerzählung geben und schließt daher (ebd. 32f.) das Poetische aus dem Bereich des Fantastischen aus, obwohl die von ihm genannten Kriterien nicht notwendig gattungsabhängige Gültigkeit haben: sowohl die implizite Frage nach dem Status der Erictho (oder des Sextus, vielleicht sogar angesichts der "transhumanen" Zeichnung auch der übrigen Figuren) als auch die von der Sprecherfigur thematisierte Unschlüssigkeit hinsichtlich der Deutung des Berichteten (von Todorov ebd. auch semantisch verstanden, insofern es sich um die Bewertung von Wahrnehmungen handelt, die im Bellum civile offenbar entsprechend der Idee, daß das Fantastische nur so lange währt wie die Unschlüssigkeit [Todorov ebd. 40], problematisch bleiben, allerdings nicht im sinne einer Unterscheidung zwischen "real" und "übernatürlich", sondern einer solchen zwischen mimetisch und textuell) entsprechen Todorovs Beschreibung der fantastischen Texte, und auch die zumindest fragliche Bereitschaft der Leser, die Figuren allegorisch zu deuten, weist Gemeinsamkeiten mit Todorovs drittem Kriterium auf. Nicht diskutiert werden kann in unserem Zusammenhang, ob die Ausbildung der naturwissenschaftlich-technischen Diskurse im 19. Jahrhundert zwingend an die Beobachtungen zum Fantastischen gebunden sein muß, oder nicht vielmehr der Kontrast unterschiedener Beschreibungsweisen in zahlreichen Literaturen produktionsästhetisch genutzt worden ist, um das Phänomen der Unvereinbarkeit zu erläutern.

38. Mehrfach wird kallimacheische Programmatik zitiert (z.B. im Flüssekatalog): Wider "besseres" (geographisches) Wissen versetzt der Sprecher den Aoos aus dem nördlichen Epirus nach Thessalien (6,361f.) und transportiert in der Beschreibung (purus, parvi gurgitis) ebenso kallimacheische Bildersprache wie in der Parallele zum Apollonhymnus bei der Schilderung des Amphrysos (6,367f.; die Bezüge nennt Korenjak [1996] 93 z.u 6,361f. und 95 zu v. 6,367f.). Dies verweist auf eine in der detaillierten Entfaltung der Phänomene im Bell. civ. erkennbare Auseinandersetzung mit kallimacheischer Poetologie, die durch die Privilegierung der Epik als Bezugsrahmen noch nicht ausreichend gewürdigt werden konnte.

39. Zur Rede von Irrtümern und ihren Anlässen im Thessalienpassus s. Masters (1992) 150-178. Die Vereinigung von verstreut lokalisierten Mythen entspricht der gängigen poetischen Technik der kontaminierenden Imitation verschiedener Vorbilder, hat also strukturell kein überraschendes oder neues Element an sich, der selbstreferentielle Bezug auf die Unglaublichkeit der Konstruktion, wie ihn der Sprecher als Figur unterstreicht, dürfte weniger Konventionalität beanspruchen.

40. $\mathrm{Zu}$ Ovids Flüssekatalog s. Korenjak ad loc. und zur Bedeutung Ovids für die Einbindung der lehrhaften Wissenselemente dezidiert Schrijvers (2005), bes. S. 32 (mit Verweis auf Lausbergs Bezeichnung Ovids als "Einfallstor" für das Lehrhafte im Bell.civ.).

41. Geographische Konfusion ist ein Merkmal des Textes, dessen Effekte beschrieben werden können, über das Wissen oder Unwissen des (historischen) Verfassers läßt sich keine wissenschaftliche Aussage treffen. Der vates oder eine poetische Sprecherfigur können im Vertrauen auf die eigene Wahrheit der Dichtung auf Beglaubigungsstrategien wie Augenzeugenschaft, Überprüfbarmachung und Übereinstimmung mit "Fachpublikationen" verzichten. Zur Konstruktion der Landschaft vgl. Masters (1992) 150-178, der ebd. 176f. zum Ergebnis kommt, daß die Konfusion nur mit eingehender Kenntnis bewerkstelligt werden kann.

42. Dazu eindrücklich Schrijvers (2005) 36-39.

43. Er komme, so leitet es der Sprecher her, unmittelbar aus dem Unterweltsfluß Styx hervor, vermische sich nicht mit unwürdigen, bloß irdischen Flüssen, so daß in ihm die Unterwerfung der Götter unter die eidbindenden Kräfte des Styx nach Thessalien transportiert werde - letztlich damit das Land aus dem Herrschaftsbereich der superi heraushebend.

44. fama est als formelhafte Iuxtaposition (nur diese als Bsp.) ist geläufig seit z.B. Lucr. (z.B. 5,14. 5,392. 5,411.) Verg. Aen. 3,578. 3,694. 6,14. 8,600. 10,636. Ov. met. 2,265. 3,694. 4,305. 9,316. 15,356. Lucan hat es noch einmal in 9,136, vielleicht zusätzlich motiviert durch Sen. Thy. 668 in 
ähnlichem Kontext), eine Abwandlung (famae si creditur) z.B. 3,220. Zur metapoetischen Nutzung von fabula/ causa und fama (= "the chosen version of a literary tradition at a given time", worin variable Stimmen, Alternativversionen und Fragmentierung enthalten bleiben) vgl. Papaioannou (2005) 233f.

45. Woldemar Görler danke ich herzlich für zahlreiche Hinweise zu den Implikationen solcher Einschaltungen und die Literaturangaben: Bömer $\mathrm{zu}$ Ov. met. 3,266. fast. 2,4; Schrijvers, Miscellanea Tragica (FS Kamerbeek), 415f.; Görler, Caesars Erzählerstandort, 116 A. 50E.; Bömer fast. Einl. S. 49 zu 4,347. 6,435 (Beglaubigung). Zu creditur T.C.W. Stinton, Si credere dignum est, in: Proc. Cambr. Phil. Soc. 22 (1976) 60-89; N. Horsfall, Virgil and the Illusory footnote, Papers of the Leeds International Latin Seminar 6 (1990) 49-63. Käthe Friedemann, Rolle des Erzählers, 86f.; Ov. 1,8,12; Kroll zu Catull 64,2 und 124; Heinze, Ovids elegische Erzählung, 92f.; creditur in Verg. Aen. 6,14 (Austin mit Lit.), Aen. 6,173; Lucan 9,411.

46. Vgl. Pomponius Mela, De chorographia 2,36 terrae interiores claris locorum nominibus insignes paene nihil ignobile ferunt. hinc non longe est Olympus, hic Pelion hic Ossa, montes gigantum fabula belloque memorati; hic Musarum parens domusque Pieria; hic novissime calcatum Graio Herculi solum saltus Oetaeus; hic sacro nemore nobilia Tempe; hic Libethra carminum fontes. Zur reichen literarischen Tradition z.B. der Berggruppe Ossa, Pelion und Olymp (Gigantenkontext): Verg. georg. 1,281-283. Prop. 2,1,19f. (Recusatio). Ov. am. 2,1,13f. (Rückschau/ recusatio); fast. 1,307f.; fast. 3,441f.; met. $1,154 f$.

47. Diese letzte Bestimmung ist ambivalent: als Simplex für das Kompositum corripere bezeichnet rapuisset das Zusammenraffen der Glieder und die Klage betrifft die Unvollständigkeit des Begräbnisses. Aber da sie selbst die Verstümmelung ihres Sohnes im Wahn vollzogen hat, klingt als weiteres Kompositum das "Heraus-" "Wegreißen" (eripere) nach, und so beklagt sie auch, daß sie im Akt des Zerfetzens seines Körpers nicht mehr Glieder hatte abtrennen können, die sie nun bestatten könnte. Zum Zitat der literarischen Tragödiengattung im Agave/ Pentheus-Motiv s. Ambühl (2005) 272-275 (ebd. 273 mit Anm. 39 zur Bedeutung von exul als "wahnsinnig”).

48. Vgl. den Bericht des Sextus über den Tod des Vaters in Bell. civ. 9,141-143 und die Schilderungen des zerstörten Körpers in 8,663-691. 775-778. 786-793 u.a. Der Caesarbezug wird zudem durch die Wiederaufnahme des Motivs im siebten Buch gesichert, wo Caesars Heimsuchung von den Rachegeistern nach der Schlacht mit den Qualen des Pentheus und der Agave verglichen wird (7,797f.): Nec magis attonitos animi sensere tumultus,/ cum fureret, Pentheus, aut, cum desisset, Agaue. Zur Metaphorik der Abtrennung des caput (Zerstörung des caput mundi) vgl. oben und zum festgeprägten Motiv Serv. zu Verg. Aen. 4,469 prima autem Agave mater eius amputasse caput dicitur, feram esse existimans. Die Dido-Passage ist nicht nur hier in direkter Imitation präsent, sondern bildet auch einen zentralen Subtext für die Infragestellung der gesamten Begegnungsszene Erictho/ Sextus im wahnhaften videre (s.u.).

49. Vgl. Korenjak (1996) 91 zu vv. 6,357-59 (verstanden als "Vorverweis"). Bereits im Prodigienkatalog war Agaves Wahn vermerkt worden, und zwar als von einer Erinye verursacht, wie sie auch das drohende Verderben für die Römer ankündigte (1,572-575): ingens urbem cingebat Erinys/ [...] Thebanam qualis Agauen/ impulit. Vgl. auch Ambühl (2005) 275 zur Relation der Passagen ("Verweise", "Entwicklung").

50. Zur Versetzung Thebens nach Thessalien vgl. Ambühl (2005) 274.

51. Vgl. 1,123-26 te (sc. Caesar) iam series ususque laborum/ erigit inpatiensque loci fortuna secundi; nec quemquam iam ferre potest Caesarve priorem/ Pompeiusve parem. Im folgenden über Pompeius $1,129 \mathrm{f}$. alter vergentibus annis/ in senium.

52. Korenjak (1996) 102f. zu vv. 393f. schlägt eine stärker symbolische Lektüre vor und erwägt zum einen, daß Chiron als das Sternbild Schütze auf den plötzlichen Fall mächtiger Persönlichkeiten bezogen sei (mit Verweis auf Man. 4,560-67), und daher auf Pompeius" Krieg gegen den übermächtigen Caesar insgesamt bezogen werden kann. Zum anderen nennt er einen möglichen Bezug (Nero Schütze, Lucan Skorpion) auf die Bedrohung des Dichters durch Nero - 
dies scheint weniger plausibel, zumal die Attributionen gute Parallelen zu Pompeius und Caesar implizieren.

53. Ein anonymer Leser für "Dictynna" weist mich zu Recht darauf hin, daß Pompeius sonst im Text mit der Flucht, nicht mit dem Angriff assoziiert ist. Hier könnte eine schwächere Deutung des impetere als Bezeichnung des sich vor dem Kampf dem Gegner Zuwendens sowie die unterstützende "Schwächung" des Chiron/ Pompeius durch senex und gelidus (zu möglichen Anklängen an die Todeskälte vgl. z.B. Bell. civ. 6,629 gelidas leto [...] medullas) den möglichen Widerspruch abmildern, auch wenn jedenfalls die Ausgangsposition der Gegner auf dem Schlachtfeld davon unberührt im Sternbild aufgegriffen bleibt.

54. Lucan hat auch hier (s.u.) Senecas Thyestes vor Augen, in dessen Chorlied vv. 789-874 die Weltuntergangsvision neben dem Thessalienmotiv (vgl. Thy. 810-813 zu Thressa, Pelion und Ossa auch mit Bell. civ. 6,334-337. 347f. 411f.) die dynamische Beschreibung des Verhältnisses von Scorpion und Chiron vorgeprägt hat (Thy. 858-862): iustaeque cadent pondera Librae/ secumque trahent Scorpion acrem./ et qui nervo tenet Haemonio/ pinnata senex spicula Chiron,/ rupto perdet spicula neruo. Anders ist die Darstellung des geordneten Laufes durch Germanicus (vgl. Arat. 637 Chiron pius), der aber auch die Abfolge der Sternzeichen in den Bildern von Vertreibung und Flucht beschreibt (vgl. z.B. 645 scorpios Oriona fugat, pavet ille sequentem).

55. Vgl. die Formulierung dieser Lesbarkeit gemäß der Sympatheia-Lehre in Bell. civ. 7,202-04 si cuncta perito/ augure mens hominum caeli nova signa notasset,/ spectari toto potuit Pharsalia mundo.

56. Korenjak (1996) 99 zu vv. 6,381-94.

57. Der gesamte Katalog zum Kosmischen wird im Perfekt gehalten (bis 6,486), das sowohl chronologisch die Auswirkungen der magischen Eingriffe zu verorten geeignet als ihre dauernde Prägung des Landes im Resultat festzuhalten vermag, nur unterbrochen von der eindrücklichen Schilderung der Ohnmacht Iuppiters (6,465 miratur, complent; 466 praeducunt; 467 tonat ignaro caelum Iove). Die synkopierte Form auch häufig mit cum inversum und ähnlichen zur Überleitung geeigneten Konstruktionen, vgl. aus den zahlreichen Bsp. bei Lucan 8,14-16 cum peterent ... stupuere ... attoniti; 6,573-575 ministri ... vagati/ conspexere ... sedentem.

58. Vgl. 6,481-84 terra quoque inmoti concussit ponderis axes,/ et medium uergens titubauit nisus in orbem./ tantae molis onus percussum uoce recessit/ perspectumque dedit circum labentis Olympi. Die Aeneis-Parallele vermerkt Korenjak (1996) ad loc.

59. Thessalien ist gegenüber den Teilbezeichnungen Haemonius, Emathius und Pharsalos auffällig häufiger im Bell. civ.: 52 Belege für Thessalicus/ Thessalia/ Thessalus (erstmals im Truppenkatalog 3,192, dann 4,528 Thessalicas sagittas; das Fortwirken zeigen die späten Belege, die hyperbolisch die Bedrängnis Caesars im ägyptischen Palast mit dem Geschehen in Thessalien kontrastieren, vgl. 10,449 Audax Thessalici nuper qui rupe sub Haemi [...] und 10,474 Non Thessala tellus [...] tantum ausus scelerum ), während Haemonius (u. Ableitungen) mit 19 (erstmals in 1,680 in der Vision Philippis/ Pharsalos", dann ebenfalls im Truppenkatalog 3,192 [Thessalus Haemoniam vomer proscindit Iolcon], letztmals vor 10,449 (s.o.) in der Flucht des Pompeius 8,2 Haemoniae silvae) und Pharsalos/Pharsalia/ Pharsalicus mit 22 Belegen zusammen noch seltener sind (Pharsalprogrammatisch zuerst in 1,38, letztmals metapoet. in 9,982 Pharsalia nostra/ vivet). Die konstanteste Verwendung weist Emathius (+ Verwandtes) auf: Vom ersten Vers an in 34 Belegen zieht sich seine Präsenz bis zum zehnten Buch $(10,58)$, mit einer deutlich über das siebte Buch hinaus reichenden Frequenz: 2x im ersten (Ankündigung 1,1 und Vision in 1,686), dann einmal in vier $(4,256)$, es folgen das sechste (6x), siebte (8x), achte (9x), neunte (7x) und zehnte (1x).

60. Relevant ist dabei die Beobachtung, daß es nicht Caesar ist, der die Ruchlosigkeit der Landschaft bewirkt, denn er selbst steht hinter deren Macht zurück: der triumphale Frevel seiner Taten, die den vom Dichter konstruierten, überzeitlichen Charakter des Schlachtfeldes als einer Totenlandschaft lediglich in das visuell Wahrnehmbare konkretisiert haben, mit Leichen und Blut als Elementen der Landschaft (7,789-795 propulsa cruore/ flumina, aequantia colles/ corpora, Emathiam non cernere terram, campos sub clade latentes), gipfelt in dem Angebot, diese Landschaft 
dem selbst schuldigen Himmel als Dankesopfer darzubringen (7,798f. caeloque nocenti/ ingerit Emathiam), aber am Ende behauptet sich das Totenreich gegen den Frevler und entzieht dem Sieger die Macht (7,823f. Sed tibi tabentes populi Pharsalica rura/ eripiunt camposque tenent victore fugato).

61. $\mathrm{Zu}$ den Armeen der Toten s. Bell. civ. 6,633-36 Si tollere totas/ temptasset campis acies et reddere bello/ [...] extractus Stygio populus pugnasset Averno.

62. Einem anonymen Leser für "Dictynna" verdanke ich den Hinweis auf die Verarbeitung dieses Motivs in der Schilderung des rasenden tyrannus Mezentius in Verg. Aen. 8, 485f. (mortua quin etiam iungebat corpora uiuis/ componens manibusque manus atque oribus ora).

63. Die Erinnerungen des alten Mannes ordnen die Ereignisse zu einer grausamen Abfolge einander unter wechselnden Herrschaften (Marius, Sulla) identisch bleibender Tötungsszenarien, denen das Wogen der Schlachtreihen in epischen Kampfesschilderungen als Schema zugrundeliegt - vgl. die Neueinsätze 2,98. 134. 139. 173). Damit schafft der Sprecher eine Deutungsfigur des Identischen, die die Rede von den Totenarmeen genauso vorwegnimmt wie die zentrale Stellung des Toten in der Konstruktion des inneren Zentrums des Werkes: Das Wesen der inneren Entzweiung kommt in der Forterzählung der Schlacht hinein in die Zerlegung der Toten zum Ausdruck. In gleichem Verhältnis der Emergenz aus den Figuren des zweiten und sechsten Buches steht dann auch der herbeigerufene Tote (6,758f. nondum facies viventis in illo/ iam morientis erat).

64. Unabhängig von allen Übereinstimmungen in Einzelbeobachtungen unterscheiden sich die Lucanforschungen jeweils nach der verwendeten Terminologie (und damit Vorstellungswelt) für die Bestimmung der Bezüge (Verweis, Ähnlichkeit, Steigerung, Entwicklung etc.) und ihres außerliterarischen Bezugspunktes (Politik, Geschichte, Poetik etc.), vgl. z.B. Henderson (1987) über das Modell des "recycling" von Gewalt im Bell. civ.

65. Vgl. zu den Geisterheeren Ericthos dieselbe Erscheinung in den Prodigien des ersten Buches (wo ebenfalls die Erinye bereits genannt war) Bell. civ. 1,569f. Tum fragor armorum magnaeque per avia voces/ auditae nemorum et venientes comminus umbrae.

66. Glaubwürdigkeit (quidquid creditur) als an der Alltagserfahrung orientierte Vorstellungskraft konnte also auch vor dem postulierten historischen Beginn der Ausdifferenzierung von Diskursen als Kriterium gegen die Gültigkeit einer Imagination ins Feld geführt werden.

67. Das prosaische licentia hat erst Lucan öfter in der Dichtung verwendet (s. 1,8 licentia ferri. 6,268. 9,1073). Den doppelten poetologischen Bezug unterstützt die engste Parallele des Hexameterschlusses bei Ov. ars 1,387f. Hoc unum moneo, siquid modo creditur arti,/ Nec mea dicta rapax per mare ventus agit.

68. Spätestens in der Äußerung des Sprechers, Erictho hoffe (6,585 sperat), die Leichen Caesars und des Pompeius in Pharsalos verstümmeln zu dürfen (6,587f.), werden Unwissen der Figur und die Notwendigkeit einer Aporie der Nekromantie sichtbar, so daß die folgende Verbindung der Textkomposition durch Retardation mit dem Thema des unmöglichen Wissens eine weitere Beschäftigung des Textes mit seinen eigenen Grundlagen markiert (Ericthos Unwissen, das Scheitern ihrer Künste, der Widerwille des unwissenden Toten [der Tote soll vor dem Orkus abgefangen werden [6,714f. primo pallentis hiatu/ haeret adhuc Orci]], die mühsame Konstruktion der Totenbotschaft). Erictho fragt den Toten nach Botschaften aus der Unterwelt, in die sie selbst vorher solche geschickt hat (6,568f. gelidis infudit murmura labris/ arcanumque nefas Stygias mandavit ad umbras). Noch stärker ist die Rückwendung der Aussage auf den Text selbst in Ericthos Grundlegung des Wissens, das sie von dem Toten erfahren möchte: durch einen Zaubergesang (carmen) versetzt sie den Toten in die Lage, im Text des Bellum civile Auskunft zu geben (6,775f. Addidit et carmen, quo, quidquid consulit, umbram/ scire dedit).

69. Vgl. u. zur veritas poetica, zur licentia und z.B. die ironische Instrumentalisierung der auf dem Primat des historisch Belegten beharrenden Lesererwartungen in Ov. am. 3,12,41-44 Exit in inmensum fecunda licentia vatum / Obligat historica nec sua verba fide;/ Et mea debuerat falso laudata 
videri/ Femina: credulitas nunc mihi vestra nocet. Vgl. auch Beteuerungen wie Ov. fast. 6,661f. haec quoque, quam referam, nostras pervenit ad aures/fama, nec a veri dissidet illa fide.

70. Bell. civ. 6,624-26 dixerat, et noctis geminatis arte tenebris/ maestum tecta caput squalenti nube pererrat/ corpora caesorum tumulis proiecta negatis.

71. Zur Diskussion der bereits von O"Higgins (1988) vorgeschlagenen Deutung als Vorwegnahme vgl. Korenjak ad loc., polemisch von Narducci (2002) 147 Anm. 82 zurückgewiesen, vgl. auch Finiello (2005) 180 (Erictho bringt das Schlachtfeld magisch hervor).

72. Vgl. bell. civ. 7,793f. locus, uoltus ex quo faciesque iacentum/ agnoscat; 7,797-99 ac, ne laeta furens scelerum spectacula perdat,/ inuidet igne rogi miseris, caeloque nocenti/ ingerit Emathiam.

73. Die Sonne hat hier den Leichen noch nicht zugesetzt (6,622 nec membris sole perustis), was den Übriggebliebenen erst nach dem grausigen Mahl der Tiere im siebten Buch geschehen wird (7, 845f. sol ... Emathiis resolutam miscuit arvis). Die Leichen (6,626 corpora caesorum proiecta) prüft Erictho mit wissenschaftlichem Eifer (6,629-31 eligit, scrutata, invenit, quaerit), während Caesar die Blutflüsse und Leichenberge (7,790f. excelsos cumulis aequantia colles/ corpora ... acervos) als neuartige Landschaft genießt, die die alte verdeckt, und die Toten mustert und akribisch zählt, um seinen Triumph auszukosten (7,789-795 cernit, spectat, numerat, lustrare).

74. Vgl. 6,627-31 continuo fugere lupi, fugere reuolsis/ unguibus inpastae uolucres, dum Thessala uatem/ eligit [...] und 7,825-29 non solum Haemonii funesta ad pabula belli/ Bistonii venere lupi tabemque cruentae/ caedis odorati Pholoen liquere leones./ tunc ursae latebras, obscaeni tecta domosque/ deseruere canes; 7,836-37 omne nemus misit uolucres omnisque cruenta/ alite sanguineis stillauit roribus arbor. Sowohl das Motiv der Konkurrenz zwischen Tieren und Erictho als auch die grausigen Details der Zerstückelung waren als überzeitlich-typische Kennzeichen der Hexe in 6,550-553 eingeführt worden und bereits dort mit dem zweiten Leitmotiv der unbestatteten Körper verknüpft: $E t$ quodcumque iacet nuda tellure cadaver/ ante feras volucresque sedet; nec carpere membra/ volt ferro manisbusque suis, morsusque luporum/ exspectat siccis raptura e faucibus artus. Erictho unterbricht den natürlichen Lauf, indem sie beide Male den Tieren ihr Mahl entreißt und diese ungesättigt bleiben (6,653 siccis; 6,628 impastae).

75. Bell. civ. 6,716-718 Ducis omnia nato/ Pompeiana canat nostri modo militis umbra,/ si bene de vobis civilia bella merentur.

76. Schrempp (1964) 51-53; ebd. 53 mit Anm. 116 hat Schrempp die Argumente geprüft und gezeigt, daß Lucan sich die Verbindungen "in weit größerem Ausmaß als seine literarischen Vorbilder" zunutze gemacht hat. Ohne die absichtliche Identifikation könnte die Entfaltung des Gedankens einer zeitlich unabhängigen Wiederholung desselben unter denselben Voraussetzungen nicht gelingen: Die Fortsetzung des Krieges soll als Wahrnehmung einer inneren Einheit kenntlich werden (7,853f. Ante novae venient acies, scelerique secundo/ praestabis [...] campos; 7,868 si non prima nefas belli, sed sola tulisses).

77. Bell. civ. 7,591f. Nec tibi fatales admoveris ante Philippos,/ Thessalia periture tua (im preisenden Anruf des Brutus, der den Aufstieg Caesars bis zum Tyrannen abwarten soll, 7,596 vivat et ... regnet).

78. Sie sieht Pharsalos (1,679-682), Ägypten (1,683-686), wo sie den verstümmelten Körper des Pompeius im Sand erkennt (1,685f. hunc ego, fluminea deformis truncus harena/ qui iacet, agnosco), dann nach Libyen, zurück über Alpen und Pyrenäen und nach Rom, wo im Senat der frevelhafte Krieg ein Ende findet (1,690f. patriae sedes remeamus in urbis/ impiaque in medio peraguntur bella senatu).

79. Pangaea saxa stehen in 7,482 zusammen mit Pindus und Oetaeus/ Oete, davor (7,480f. gaben Haimos und Pelion den Widerhall der Waffenklänge, die räumlichen Raffungen entsprechen denen in der Thessalienkonstruktion (s.o.; der Pangaios in Makedonien, der Pelion in Thessalien, Haimos in Thrakien).

80. Der wahnsinnigen Frau folgt der Sprecher in der Darstellung der Absichten Ericthos (als erlebter Rede?), die den Krieg wegen der zu erwartenden Toten nicht weiterziehen lassen will 
(6,582 vetuit transmittere bella Philippos), wobei der doppelte Bezug einen guten Sinn ergibt, denn er verweist auf die ein weiteres Mal für Erictho zu erwartende Ernte und beide wird sie sich nicht entgehen lassen wollen. Wenn schließlich Cato unerbittlich auf der Fahnentreue besteht und damit ein früheres Ende des Mordens verhindert (9,271 credet [sc. Caesar] ab Emathiis primos fugisse Philippis), unterstreicht die Junktur Emathiis Philippis explizit die Konstruiertheit der Identität, die über den zeitlichen Abstand hinweg den Fortgang der inneren Zerfleischung des Gemeinwesens festhält. Vgl. zur Einbindung des Abschnittes auch Leigh (1997) 296-303. Mit dem Schritt von der Trennung zur Identität als poetischer Vorstellung kann somit auch das ergänzt werden, was Schrempp (1964) 131 in chronologischen Kategorien als "innere Beziehung" zwischen den Kriegen beschrieben hat, als "das Beispielhafte der früheren Bürgerkriege und die Wiederholung und Fortführung des erzählten bellum civile in den späteren Kämpfen”.

81. 6,649-53 (sedit iners), maestum mundi confine latentis/ et nostri, quo non metuant admittere manes/ Tartarei reges. Nam, quamvis Thessala vates/ vim faciat fatis, dubium est, quod traxerit illuc/ aspiciat Stygias an quod descenderit umbras. Vorstellungen von geschützten, sakralen Räumen sind in den durchlässigen Orts- und Zeitkonstruktionen Lucans unwirksam, so daß die Präsenz z.B. der Rachegeister als dauerhaftes Moment gezeichnet werden kann (vgl. zur Relevanz der sakralen Schwellen und Grenzen den Hinweis des Servius zu Verg. Aen. 4,473 SEDENT IN LIMINE DIRAE a Pacuvio Orestes inducitur Pyladis admonitu propter vitandas furias ingressus Apollinis templum: unde cum vellet exire, invadebatur a furiis [...] alii dicunt, quia, cum absolutus in templo Minervae, de iudicio exiret, a furiis conreptus est).

82. Vgl. zur Unbestimmtheit als Element des Fantastischen T. Todorov (1975). Von der Unbestimmtheit als poetischer Qualität sind Kommentare des Sprechers zur Unfaßbarkeit (z.B. 6,492-499) abzusetzen.

83. Vgl. zum prägenden Motiv des Irrens in weiten Räumen: Sextus schreitet in die verlassenen Gegenden (6,573 deserta per arva/ carpit iter), Sextus" Diener irren unwissend auf der Suche nach Erictho (vagati), Caesars furor treibt ihn zu einem rasenden Ortswechsel in der Schlacht (7,558 f. agmina circum/ it vagus; 7,567 vagatur), Pompeius irrt auf der Flucht vergeblich umher, um Thessalien hinter sich lassen $\mathrm{zu}$ können (8,4f. Magnus agens incerta fugae vestigia turbat/ implicitasque errore vias). Zu Allgegenwart vgl. Hömke (1998) 137 mit Verweis auf Glaesser (1984) $63 \mathrm{f}$.

84. Vgl. 6,333f. Thessaliam, qua parte diem brumalibus horis/ attollit Titan, rupes Ossaea coercet; 6,395 Hac tellure feri micuerunt semina Martis; 6,413f. Hac ubi damnata fatis tellure locarunt/ castra duces; 6,438f. Thessala quin etiam tellus herbasque nocentes/ rupibus ingenuit.

85. Einen guten Überblick zu den dynamischen Ausdrucksweisen in Lucans Thessalienkonstrukt bietet Korenjak (1996) 79-81 zu 6,333-412 (zum “anthropomorphisierenden” Ausdruck ebd. 80, allerdings mit Verweis auf stoische Philosophie nach Schönberger [1960]). Der auch hier noch wirksamen Rede von der Sorglosigkeit und den Fehlern der Darstellung wird man aber nicht folgen wollen, um nicht in die beschriebene Leitvorstellung von einem "Tatsächlichen" und seiner sekundären Umformung zu geraten.

86. Zu fama loci verweist W. Görler mich auf die Entsprechung in Verg. Aen. 3,294 (incredibilis ... fama), zumal "in beiden Fällen die unerwartete Gelegenheit zu einem Blick in die Zukunft" aufgetan wird (vgl. auch [ohne szenische Entsprechung] den Hexameterbeginn Verg. Aen. 7,333 fama loco). Zur Übereinstimmung mit einer ovidischen Begegnungsszene s.u.

87. Bell. civ. 6, 434f. vanum saevumque furorem/ adiuvat ipse locus vicinaque moenia castris/ Haemonidum; 570 Hanc ut fama loci Pompeio prodidit. Lucan hat die Junktur noch in 8,14 fama nondum prodente (sc. das bereits Vergangensein dessen, was die nach Pharsalos strebenden Truppen noch als zukünftig erwarten), sonst ist sie vor Lucan wenig verbreitet, ein wegen des interessanten Kontextes (über sichere Anzeichen des Todes und die Frage unvorhersehbarer Genesungen) ist Cels. med. 2,6 Illud interrogari me posse ab aliquo scio: si certa futurae mortis indicia 
sunt, quomodo interdum deserti a medicis convalescant, quosdamque fama prodiderit in ipsis funeribus revixisse?

88. Vgl. Korenjak [1996] $155 \mathrm{zu} 6,570$ mit Verweis auf die Vorstellungen von einer Schicksalsmacht, die für das Geschehen an einem Ort zuständig ist (nach Bömer zu Ov. fast. 1,209) und auch dem Bannen des Bürgerkrieges an Pharsalos durch Erictho entsprächen. Der hier überlegte Ansatz ist prinzipiell verschieden davon, weil nicht auf mögliche magische Vorstellungen zurückgegriffen wird, sondern nur das Verhältnis zwischen Textumgebung und Textverdichtung (Figur) untersucht werden soll.

89. Aus der verfluchten Erde gehen Pflanzen für die schwarze Magie hervor, das Land bringt die Hexen als Bewohnerinnen hervor, es verstärkt die okkulten Interessen des Sextus zu einem Wahn - furor, aus der Vervollkommung der magischen Künste entsteht Erictho, die örtliche Kunde bringt die Protagonisten zusammen. Wie stark unser poetisches Vorstellen von der Dichotomie Beobachter- Gegenstand und einem "Hinein" in die Gegenstände statt eines "Heraus" in einem Relief geprägt ist, zeigen die Übernahmen aus der Sprache der Filmtechnik: Korenjak (1996) 155 über Bell. civ. 6,333-570 (Thessalien bis Erictho) als "Zoom" (darin folgt auch Finiello [2005] 159) schließt: "So sind wir zugleich aus der mythologisch verbrämten Urgeschichte Thessaliens bis in die historische "Realität" gelangt". Darin kommt die Paradoxie der Szene zum Ausdruck, denn der Endpunkt der Herleitung der Gegenwart endet in einem überzeitlichunfaßlichen Hier und Jetzt der Poesie, in der das Historische nicht mehr als eine marginale Kulisse abgibt.

90. Damit stehen die Landschaften und Ereignisse in einem noch engeren Verhältnis zueinander als es z.B. Green (1991) 246 höchst anschaulich am Übergang des Rubicon gezeigt hat. Im Begriff der Ekstase überlagern sich die verschiedenen Bedeutungssschichten des Heraustretens aus einem Untergrund und dem "Vernünftigen" im Sinne der tranceartigen Verzückung, der höchsten Erregung und der Trennung von Leib und Seele nach der hagiographisch-mystischen Tradition (vgl. zum Ganzen Art. Ekstase in HWPh 2 [1972] 343-436).

91. Bell. civ. 6,419f. turbae sed mixtus inerti/ Sextus erat, Magno proles indigna parente; 6,593f. non ultima turbae/ pars ego Romanae, Magni clarissima proles. Sextus teilt mit der Sprecherfigur zudem die Unruhe (6,424 impatiensque morae), die keinen Aufschub des Wissens zu ertragen vermag $(6,423$ fati praenoscere cursus [aufgegriffen in 6,615 si praenoscere casus], 424 venturisque omnibus aeger), und trägt damit paradoxerweise genauso wie der Sprecher zur narrativen Verzögerung bei. Obwohl auch der Sprecher den superi jeglichen Einfluß auf das Geschehen und sogar das Wissen um seinen zukünftigen Verlauf abspricht, tadelt er Sextus für dessen (verständliche?) Hinwendung $\mathrm{zu}$ anderen Mächten. Die Götter, die zu fragen von Moral und Gesetz erlaubt ist (6,430 fas erat), sind nach Ansicht beider nicht kompetent (6,434 scire parum superos), was der Sprecher durch die zum eigenen Substrat verknüpften mantischen Szenen des Werkes sukzessive untermauert (Appius scheitert mit seinem Besuch des Orakels von Delphi, Sextus mit Erictho, theoretisch begründet lehnt Cato im neunten Buch die Befragung des Ammonorakels ab). Zum Konnex vgl. die Synthese bei Narducci (2002) 107-155.

92. Anders z.B. Narducci (2002) 128 mit Anm. 88.

93. Bell. civ. $8,204 \mathrm{f}$. primusque a litore Lesbi/ occurrit natus (auch die im vorherigen Vers gegebene Beschreibung sparsus ab Emathia fugit quicumque procella verwischt dem historiographisch kundigen Leser nicht die Mehrdeutigkeit). Vgl. auch Masters (1992) 209 mit Anm. 62 (darin Literaturangaben und sein Fazit: "Sextus has been chosen because he cannot be there."

94. Vgl. die nüchterne Beobachtung bei Hygin. mythogr. fab. 31, 7 Achelous fluuius in omnes figuras se immutabat. Zahlreiche Belege für figura als beliebig austauschbare äußere Gestalt (z.B. von Göttern angenommene) z.B. in ThLL VI 725, 7-21. Zur Fortuna loci Bömer zu Ov. fast. 1,209 (zustimmend Korenjak zu 6,570).

95. Vgl. Cic. de orat. 2,357 über die Veranschaulichung des Abstrakten (am Beispiel der visualisierenden Gedächtniskunst): vidit enim hoc prudenter sive Simonides sive alius quis invenit, ea 
maxime animis effingi nostris, quae essent a sensu tradita atque impressa; acerrimum autem ex omnibus nostris sensibus esse sensum videndi; quare facillime animo teneri posse, si ea, quae perciperentur auribus aut cogitatione, etiam oculorum commendatione animis traderentur; ut res caecas et ab aspectus iudicio remotas conformatio quaedam et imago et figura ita notaret, ut ea, quae cogitando complecti vix possemus, intuendo quasi teneremus.

96. Die unmittelbare Erfahrung des Visuellen wünscht sich Seneca für die Philosophie, die er sich sehnsüchtig (jenseits der Fragmentierung durch die Sprache) als ganz dem spectaculum mundi ähnlich vorstellen möchte (Sen. epist. 89,1): Utinam quidem quemadmodum universa mundi facies in conspectum venit, ita philosophia tota nobis posset occurrere, simillimum mundo spectaculum.

97. Rutilius Lupus, Schemata dianeseos et lexeos 2,6 Nam humana figura produxerunt personas, quae in veritate artis et voluntatis sunt, non personae.

98. $\mathrm{Da}$ es uns nicht darum gehen kann, das Poetische als unbestimmbares Raunen gegen die Vernunft ins Feld zu führen (es aber eben dessetwegen unzulänglich ist, alle Texterklärung gemäß einem bloß bildlich-übertragenen Sprachgebrauch auf "logische" Relationen zu reduzieren) mag Rosenkranz" Referat (1853/ 1990) 247 der aufklärerischen Stellungnahme Lessings in Erinnerung rufen: «Lessing hat bekanntlich gesagt, daß, wer über gewisse Dinge den Verstand nicht verliere, überhaupt keinen zu verlieren habe. Er hat aber nicht vonder Vernunft gesprochen, sondern angedeutet, daß es vielmehr sehr vernünftig sei, über gewisse Dinge den Verstand zu verlieren, den Verstand, der nämlich das Ungeheure, alle seine Grenzen Übersteigende, die Nichtexistenz der Vernunft in einem konkreten Fall, nicht fassen kann, [...]». 99. Darstellungen der Erictho u.a. Baldini Moscaldi (1976), Ahl (1976) 130-133, Masters (1992) 180-215, Korenjak (1996) 20-25, Hömke (1998) bes. 125-128, Finiello (2005) 158-165 u.a.

100. Vgl. z.B. die einzelnen Personifikationen in den Furien (in der Unterwelt zwischen Bellum und discordia angesiedelt, Verg. Aen. 6,279-81), Allectos Porträt in Aen. 7,325f. und Tisiphone in Aen. 6,570-72.

101. Bell. civ. 6,507 - 508 hos scelerum ritus, haec dirae crimina gentis/ effera damnarat nimiae pietatis Erictho.

102. Die Sprichwörtlichkeit Thessalischer Hexengesänge, wie sie in einzelnen Belegen faßbar ist, hat Lucan wohl durch seine Ausweitung auf das ganze Land und seine Bewohnerinnen wesentlich befördert, hyperbolisch z.B. schon Prop. 1,5,4-6 infelix, properas ultima nosse mala,/ et miser ignotos uestigia ferre per ignis,/ et bibere e tota toxica Thessalia; Hexenkünste in Ov. am. 3,7,27-36, darin v. 27f. Num mea Thessalico languent devota veneno/ corpora?; Sen. Phae. 421 Thessali cantus, 791 Thessalicis carminibus.

103. In der alten Diskussion über den möglichen "Wirklichkeitsgehalt" von literarischen Figuren spielt zweifellos die historisch schwer zu definierende Kategorie der "Denkbarkeit" eine Rolle. Wenn Erictho ein so hohes Maß an Unbestimmtheit aufweist, scheint dies gerade solche realistischen Argumentationen ausschalten $\mathrm{zu}$ sollen, wie sie etwa im Falle der Kyklopen angesichts der Vergleichbarkeit mit erfahrungsweltlichen Gegenständen nach dem Zeugnis des Lucilius angestellt wurden - der Sprecher selbst dürfte hier eine ironische Distanzierung vorgenommen haben (Lucil. 480-483 Marx [= 482-485 Krenkel]): multa homines portenta in Homeri uersibus ficta/ monstra putant, quorum in primis Polyphemus ducentos/ Cyclops longus pedes, et porro huic maius bacillum/ quam malus naui e corbita maximus ullast.

104. Zur Aufhebung der Trennung von Ober- und Unterwelt als Motiv (nicht als Deutungsfigur) vgl. Korenjak (1996) 43 mit Verweis auf Hardie (1993) 67-87.

105. Zur Geographie vgl. Korenjak (1996) 157 zu 6,576-582.

106. Auf die Relevanz der Begleitung von Figuren in solchen Begegnungsszenen verweist Korenjak (1996) 156 zu 6,573: Aeneas in Verg. Aen. 6,248 mit ungenannten Gefährten, Medea in Ov. met. 7,185 incomitata, Jason mit ministri $(7,255)$. Dem Hinweis ebd., Sextus werde durch den Hinweis auf Begleiter "weiblich” gezeichnet, müssten weitere Indizien beigesellt werden. 
107. Abschüssige Berghänge und hochragende Klippen sind beliebte Orte, um Figuren ihr (mythisches) Schicksal im Tod erfüllen zu lassen (vgl. z.B. die Aufzählung des Oedipus in Sen. Phoen. 12-26 Ibo, ibo qua praerupta protendit iuga/ meus Cithaeron, qua [...] 22f. vel qua alta maria vertice inmenso premit/ Inoa rupes [...]). Das römische Leitbild der vom steilen Felsen herabblickenden Frauengestalt, die von furor bestimmt ist, hat Catull mit der zweimaligen Zeichnung der Ariadne in carm. 64 geschaffen (vv. 124-127): saepe illam perhibent ardenti corde furentem/ clarisonas imo fudisse e pectore uoces / ac tum praeruptos tristem conscendere montes/ unde aciem pelagi uastos per tenderet aestus. Vgl. 64,54 indomitos in corde gerens Ariadna furores und die Beschreibung des Schauens 64,60-62 quem (sc. Theseus) procul [...]/ saxeaut effigies bacchantis prospicit, eheu/ prospicit et magnis curarum fluctuat undis (Ariadnes Weinen gleicht sie dem beobachteten Meer an [fluctuat]). Zum furor bei den anderen Figuren Lucans, die dadurch kategorial von Erictho geschieden sind, vgl. die Arbeit von Glaesser (1984).

108. Wieder scheint Lucan mit sprachlichen Konventionen der erzählenden Texte zu arbeiten (s.o. zu cessavere). Ein gängiges Schema prosaischer Darstellung von Ereignisfolgen bildet die Verbindung “als $\mathrm{x}$ in der Ferne y sah(en), tat(en) x ...", wobei der Vordersatz oft die Junktur conspicere procul enthält (Livius, Caesar u.a.). Lucan setzt dieses Schema in der Dichtung ein (z.B. Bell. civ. 3,88, 4,740).

109. Die Junktur hat bereits Verwendung in der Dichtung vor Lucan gefunden (Lukrez [3,59-64] führt die Überschreitung der gesetzlichen Grenzen [3,60f. transcendere fines/ iuris] und die Verbrechen auf die Angst vor dem Tod zurück, unsere Junktur findet sich ebd. 61 socios scelerum atque ministros. Es folgt Ovid am. 1,7,27 Quid mihi vobiscum, caedis scelerumque ministrae?), die engste Verbindung zeigt sich aber in der Prosa Ciceros, in der Invektive gegen Clodius, also der dem Sprecher im Bell. civ. gegenüber Sextus zugedachten Sprecherhaltung (Cic. dom. 6): postea quam mihi nuntiatum est populum Romanum in Capitolium propter metum atque inopiam rei frumentariae convenisse, ministros autem scelerum tuorum perterritos partim amissis gladiis, partim ereptis diffugisse, veni [...]. Vgl. zudem prov. cons. 5 iis (sc. cohortibus) praeposuit quos putavit fore diligentissimos satellites scelerum, ministros cupiditatum suarum.

110. Die prägende Bedeutung Ovids für das Bellum civile haben zahlreiche Untersuchungen der letzten Zeit erwiesen (vgl. z.B. Papaioannou [2005] zur Enthauptung Medeas im neunten Buch und umfassend Wheeler [2002]).

111. Zur Junktur carpere iter vermutet Korenjak ad loc. eine Anregung bei Verg. Aen. 6,629 carpe viam, also aus dem gängigerweise als Subtext genannten Unterweltsbesuch des Helden (dazu unten). Tatsächlich ist aber die genaue Junktur mehrfach bei Ovid belegt und dort besonders für ein feierliches Schreiten oder, noch öfter, für die Flugbewegung durch die Luft reserviert (vgl. fast. 5,87 [wie 3,603 am Pentameterende]; fast. 5,563; met. 10,605 [Hexameterbeginn]). Daß es sich um erhabene Ausdrucksweise handelt, beweist die pseudogelehrte Verwendung in Petrons sat. 116,1 hoc peracto libenter officio destinatum carpimus iter ac momento temporis in montem sudantes conscendimus, ex quo haud procul impositum arce sublimi oppidum cernimus.

112. Vgl. Ov. fast. 3,639-641 nox erat: ante torum visa est adstare sororis/ squalenti Dido sanguinulenta coma/ et "fuge, ne dubita, maestum fuge" dicere "tectum".

113. Vgl. dazu unten zum Erblicken der Erictho und der neuerlichen Nutzung Ovids.

114. Der Befehl, den Goldenen Zweig zu pflücken, kommt dem zu einer Verstümmelung gleich (Ov. met. 14,115 suo divellere trunco), Aeneas sieht (vidit in met. 14,117; wahnhaft, begehrend?) die Reichtümer des Orcus und den alten Schatten seines Vaters (met. 14,117 umbramque senilem) und lernt die Gesetze der Unterwelt genauso wie die Gefahren, die ihm in neuartigen Kriegen begegnen werden (met. 14,118f. didicit quoque iura locorum,/ quaeque novis essent adeunda pericula bellis). Das Aufsteigen in met. 14, 155f. sedibus Euboicam Stygiis emergit in urbem/ Troius Aeneas sacrisque ex more litatis/ litora adit [...]; die Hervorhebung des Rituellen (sacris) weist auf die Relevanz der Reinigung, zugleich die Gefahr deren Scheiterns. 
115. Gerichtete Bewegung in definierten Räumen, faßbare Topographien für Ober- und Unterwelt sowie die Möglichkeit der Intentionalität sind im Bellum civile nicht vorgefundene Bedingungen, denen die Figuren unterliegen, sondern von den Figuren selbst versuchsweise hervorgebrachte und scheiternde Ordnungsvorstellungen. (Landschaft istnichts vorgängig Vorhandenes, sondern textuell Erschaffenes). Als Fortschreibung erweist sich auch die Analogie abrupter Episodenenden in den Buchschlüssen von Verg. Aen. 6 und Bell. civ. 6: anstelle einer räumlichen Trennung arbeitet der Sprecher Lucans mit der Identität von Oberfläche und Untergrund, so daß an die Stelle von Aeneas" Aufstieg die Abwärtsbewegung Ericthos in die Handlungsebene als Rückkehr in die plane Textoberfläche treten kann.

116. Vgl. die Belege in ThLL V,2, 475, 41-53 (speciatim: ex inferis surgere), wo die Ovidstelle den Beginn der belegten Tradition bietet, und z.B. die ebd. unmittelbar folgende Sammlung zur Bedeutung "nascendo exire".

117. Vgl. Ov. met. 14,110-113 "Pone tamen, Troiane, metum: potiere petitis/ Elysiasque domos et regna novissima mundi/ me duce cognosces simulacraque cara parentis./ invia virtuti nulla est via." Die ovidische Sibylle steht hinter der Ermutigung der Ängstlichen, die Erictho ausspricht (Bell. civ. 6,659 ponite, ait, trepida conceptos mente timores), die poetologische Nutzung von novus (Bell. civ. 6,660 nova) und simulacra/ figura ebenfalls aus Ovids Sibyllenrede. Korenjak verweist für die exhortatio in 6,659-61 auf Ov. met. 7,332-338 (gestützt durch die von Medea initiierte Erweckung), eine Kontamination ist sicher denkbar. (Möglich sind auch isolierte Verknüpfungen wie die unmittelbar vor der Begegnungsszene verwendete [auffällige] Bezeichnung einer geheimen Botschaft der Erictho an die Unterwelt durch Bell. civ. 6,569 arcanum und das aus dem Unterweltsgang der Metamorphosen auf den Weg am Strand übertragene secretum (Ov. fast. $3,603)$.

118. Dies bildet einen wichtigen Unterschied zu der Deutung der Erictho als Bild des Dichters (vgl. Masters [1992] 205-214), die einer der vielen Varianten allegorischer Interpretation verpflichtet ist.

119. Abstraktion aus getrennten Dingen der Erfahrungswelt hin zu einer Vorstellung reiner Kulmination wird sinnfällig am Beispiel ihrer Stimme vorgeführt, die alle Laute der Tierwelt und alle Geräusche der Natur in sich vereint $(6,685-93)$, so daß sie gleichzeitig alle Stimmen und keine ist (6,693 tot rerum vox una fuit).

120. Die Fortschreibung der verwandelten Figuren in reine Ekstasen des Textes dürfte Lucan ebenfalls aus seiner Ovidlektüre entwickelt haben: dessen Suche nach den Verwandlungen und novae figurae zu Beginn und am Ende der Metamorphosen (vgl. met. 15,308 und 15, 169 novis ... signatur cera figuris) ist der Ausgangspunkt für die (vergebliche) Hoffnung der Erictho, die sie in enigmatischer (programmatischer) Weise in der Nekromantie ausspricht: Bell. civ. 6,660 Iam nova, iam vera reddetur vita figura.

121. Eine Stellensammlung bietet Dinter (2005) 300-309, zu caput 301-304.

122. Gierige Zerlegungen der toten Körper (die Nekroskopie, oftmals, aber nicht immer mit nekroptischen Motiven vollzogen) ziehen sich so konsequent durch das Werk wie die Vivisektionen der Sterbensästhetik, vgl. Arruns im Opfer Bell. civ. 1,617 raptis quaesivit in extis [es folgen die Zerlegungen der viscera 1,617. 624 hiantes viscera]; innerhalb der Sterbeszenen finden sich die Erkundungen der Vermischung beider Bereiche z.B. in 3,657f. eliso ventre per ora/ eiectat saniem permixtus viscere sanguis; die gewalttätige Inbesitznahme seiner Seherin vollzieht Apollo als ein völliges Einbrechen in ihre Glieder (5,166f. non umquam plenior artus/ Phoebados inrupit Paean), er vertreibt ihr früheres Ich aus dem Körper (5,167f. mentemque priorem/ expulit) und stößt Feuer in ihre Eingeweide (5,175 flammasque in viscera). Selbst das erinnerungsraubende Wasser des Styx gießt er ihr tief in das Innere (5,221 inmisit Stygiam Paean in viscera Lethen).

123. Vgl. Bell. civ. 2,140-143 Ille quod exiguum restabat sanguinis urbi/ hausit dumque nimis iam putria membra recidit,/ excessit medicina modum, nimiumque secuta est,/ qua morbi duxere, manus. Der kurierende Arzt erweist sich als Totengräber. Es sind Trennungen, die selbst die Sektion als 
Suche nach den ineren Bedingungen der Entzweiungsfigur induzieren (illustriert vor allem in den Trennungen des jeweiligen Hauptes [caput] von seinem Körper - Sulla, Caesar/ deren Verhältnisse radikalisiert in Pompeius" Zerstückelung etc.).

124. Bell. civ. 7,579f. Scit (sc. Caesar), cruor imperii qui sit, quae viscera rerum,/ unde petat Romam; 7,721f. tu, Caesar, in alto/ caedis adhuc cumulo patriae per viscera uadis; Cato in 2,301-03 non ante revellar/ exanimem quam te conplectar, Roma; tuumque/nomen, Libertas, et inanem persequar umbram.

125. Dinter (2005) ordnet seine Stellensammlung nach "textual, human, military, cosmic bodies", stellt aber alle in eine intentionale Beziehung zu einer am Stoff orientierten Botschaft (ebd. 308 "Lucan"s total destruction of the Roman republic").

126. Vielleicht könnte dies auch im Sinne eines Konfliktes zwischen der hinter der Sprecherfigur stehenden Instanz und der von ihr geschaffenen Figur beschrieben werden (vgl. oben): Zwischen der Überforderung der Sprache, die sich durch stilistisch produzierte Atemlosigkeit Erleichterung zu schaffen sucht, und der inneren Logik des Tuns entsteht eine Spannung, die den affektisch empfänglichen Sprecher in Widerstreit mit dem kühl berichtenden Beobachter zu setzen scheint.

127. Vgl. die Strukturierung des Abschnittes 6,537-546: v. 537 ubi servantur saxis, v. 543f. laqueum, nodosque, pendentia corpora, v. 545 cruces (percussaque), v. 550 nuda tellure. Zur Ordnung in den Selbstmordkatalogen des zweiten Buches vgl. 2,154-157 Hic laqueo fauces elisaque guttura fregit,/ hic se praecipiti iaculatus pondere dura/ dissiluit percussus humo [...] hic robora busti [...]. Erictho als Anatomin z.B. in Bell. civ. 6,629-631 eligit ... scrutata ... inuenit ... quaerit.

128. desaevire bei Lucan nur von Caesar in 5,301 und Erictho hier, effodere bei Lucan nur vom Römer und Erictho hier. Die Identität der Schlachtfelder des sechsten und siebten Buches bestimmt die auf sie bezogenen Figuren Erictho und Caesar über die unmittelbaren Parallelen hinaus als analoge Erscheinungsweisen einander über die Textfläche verbundender Konkretisierungen der Entzweiungsfigur, so daß ihre Gemeinsamkeiten nicht (im Widerspruch zum Unwillen des Sprechers, zeitliche Ordnungen anzuerkennen) als Ankündigungs- und Erfüllungs-, als Vor- und Abbildrelation oder als hyperbolische Transfigurationen auf der Geschehensebene aufgelöst werden müssen, sondern als einander bedingende, jeweils aus dem Text entwickelte Protagonisten der Entzweiungsfigur ineinander bestehen bleiben.

129. Vgl. zur Sättigung Bell. civ. 7,842-844: non intima curant/ viscera nec totas avidae sorbere medullas,/ degustant artus. Die Tiere (s.o.) stehen trotz sprachlicher und motivischer Ähnlichkeiten in der Darstellung nicht in so unmittelbarem Bezug zur Figur der Entzweiung wie Erictho (vgl. 6,540 avide desaevit in artus) und die römischen Soldaten, die römische Leichen zerstückeln, weil sich die Tiere gerade nicht um das Innere (intima viscera) kümmern.

130. Vgl. zu dieser Konzentration auch die Manipulationen am Mund einer Leiche, um ihr Botschaften für die Unterwelt zu geben (Bell. civ. 6,566-568 truncavitque caput conpressaque dentibus ora/ laxavit siccoque haerentem gutture linguam/ praemordens [...]).

131. Das Ekelhafte, als Wahrnehmung mindestens teilweise kulturhistorisch wandelbar, beschreibt Rosenkranz (1853/ 1990) 252 mit der uns bei Lucan als Leitfigur begegnenden Opposition von lebendig/ tot: "Für den Begriff des Ekelhaften im engen Sinn aber müssen wir die Bestimmung des Verwesens hinzufügen, weil dasselbe dasjenige Werden des Todes enthält, das nicht sowohl ein Welken und Sterben als vielmehr das Entwerden des schon Toten ist. Der Schein des Lebens im an sich Toten ist das unendlich Widrige im Ekelhaften." Zum Leitmotiv der Vermischung von tot und lebendig im Bellum civile s.o.

132. Vgl. die Erinnerungen Bell. civ. 2,166-190, speziell die Zerstörung des Körpers 2,177-185. Auch hier ist nicht die Verweisrelation, sondern die Gleichheit der Handlungen (wie früher die der Orte, Zeiten etc.) bis hin zur Identität zu sehen (auch das genannte rursus, iterum der rasenden Frau in 1,692f. war bereits innerhalb einer fortdauernden Bewegung des Mitgerissenwerdens verankert). Leigh (1997) 299 faßt den Zusammenhang der drei Stellen als Ausdruck einer "idea of a cycle of repetition". 
133. Die Kennzeichnung des Antonius als praesage malorum $(2,121)$ geht zweifellos nicht auf die Vergangenheit, sondern die textliche Zukunft des Pompeius im achten und neunten [Bericht des Sextus] Buch (2,122-124) Antoni, cuius laceris pendentia canis/ ora ferens miles festae rorantia mensae/ inposuit.

134. Zur Relevanz der Randbereiche und Grenzen bei der Figurenzeichnung vgl. oben die Vergleiche der antiken Rhetoren mit Eindrücken in Wachstafeln. Die Qualität der Erictho steht dabei zu den übrigen Figuren des Bellum civile nicht im Verhältnis eines wesensmäßigen Antagonismus, insofern sich auch bei Caesar, Pompeius, Cato, Scaeva, Domitius, in anderer Hinsicht auch bei den Frauenfiguren der Cornelia, Marcia und Cleopatra die Bindung an abstrakte Prinzipien weniger im Sinne der Allegorie, der Verkörperung oder gar des "Typos" beschreiben lassen, als vielmehr jeweils der inneren Motivation des Textes dienend. Dem entspricht die gegenüber epischen Vorgängern (und kaiserzeitlichen Nachfolgern) vollzogene Reduktion namentlich bezeichneter Figuren (Vgl. z.B. Sklénar [2003] 20f. und Rutz in Burck [1979] 179).

135. Rosenkranz (1853/ 1990) erkennt in der Abstraktion sogar ein sedatives Element (das Maximum an Häßlichkeit werde durch "die metaphysische Abstraktion" abgemildert).

136. Anders als z.B. Leigh (1997), Bartsch (1997) oder auch Dinter (2005) sucht diese Lektüre den Übergang auf die Stoffebene zu vermeiden, da diese (sc. das "Politisch-Historische") nur exemplifizierende Funktionen besitzt (dagegen z.B. Leigh ebd. 157: "disillusioned, excoriating meditation on the experience of history" und 306 über "empire" und "political value").

137. Trotz sprachlicher Parallelen zu den Sterbensschilderungen (z.B. der Seeschlacht in Bell. civ. 3 oder Catos Wüstenmarsch in Bell. civ. 9) setzt die Zerlegung der toten Körper qualitativ also eine eigenständige Linie fort.

138. Der Sprecher deutet die Erinnerungen des alten Mannes im zweiten Buch (metapoetisch) als Suche nach Vorbildern (Bell. civ. 2,67 magno quaerens exempla timori) und ordnet dabei bereits das konkret-Exemplarische einer Vorstellung (timor) unter, so daß die späteren Wiederaufnahmen der Schilderung aus 2,68-232 wiederum selbst als Modellfälle gelesen werden können, in denen nicht die Bestätigung der "vorahnenden Erinnerungen" des zweiten Buches, sondern eine Identität des Figürlichen erscheint.

139. Zur Nutzung der rituellen Ordnungsmuster als illustratio der Figur der Entzweiung vgl. in den Erinnerungen des alten Mannes Bell. civ. 2,170f.. 173-176. 177-185, die Erscheinungen von Pharsalos als Rachegeistern und (ungesühnte) Manen bei Caesar, seinen Soldaten, Cornelia und dem Sprecher in Bell. civ. 7 und 8 (s.o.), schließlich die Blutzeichnung des Siegers durch die von der Beute der Aasvögel herabfließenden Körperflüssigkeiten der Toten in 7,838-40 saepe super voltus victoris et inpia signa/ aut cruor aut alto defluxit ab aethere tabes/membraque deiecit iam lassis unguibus ales.

140. Korenjak (1996) $154 \mathrm{zu} 570-623$ hat auf einen allgemeinen Szenetyp mit der amüsanten Bezeichnung "boy meets girl" verwiesen, Masters (1992) 188-190 auf die Begegnung von Aeneas und Sibylle in Verg. Aen. 6,102-155. Als "primären Bezugspunkt" Lucans sieht Korenjak ebd. die Medea-Jason-Szenen (Ap. Rhod. 3,956-1147; Ov. met. 7,74-99) wegen der Motive "Magie vor einer Schlacht" und "Medea/ Erictho". Ob es sich aber um eine "Transposition ins Sinistre und Groteske", "die man geradezu als parodistisch ansprechen kann" handelt, scheint mir zweifelhaft.

141. Ov. her. 21: Vom Rufe der Insel angelockt (77 mota loci fama properabam visere Delon) verbringt Cydippe die Fahrt in Ungeduld (78-80), eilt an allen Orten vorbei (81 iam transieram ... iam) und klagt bei der Ansicht von Delos aus der Ferne die Insel an, (wie einst) fliehen zu wollen (83 quam procul ut vidi, "quid me fugis, insula" dixi). Von ihrer sedula nutrix (ministri bei Lucan) begleitet, streift sie am nächsten Tag durch die belebten Straßen (96 erramus) und wird ihrer Vermutung nach beim Schauen von Acontius geschaut (103 forsitan haec spectans a te spectabar, Aconti). 
142. Zu Bell. civ. 6,572-576 (s.o.) vgl. Verg. Aen. 4,465-470 agit ipse furentem/ in somnis ferus Aeneas, semperque relinqui/ sola sibi, semper longam incomitata uidetur/ ire uiam et Tyrios deserta quaerere terra,/ Eumenidum ueluti demens uidet agmina Pentheus/ et solem geminum et duplices seostendere Thebas, (...).Der bekannte Passus thematisiert die Auswirkungen des getrübten Sinnes (vgl. bereits zu den Omina die Dominanz der Formen von videre: Verg. Aen. 4,453 vidit. 456 hoc visum. $460 f$. [exaudiri] visa sowie das Standardmotiv der symbolhaften Dunkelheit in 461 nox cum terras obscura teneret [im Bell. civ. als Rahmenmotiv zu Beginn der Begegnung und am Buchende eingesetzt, dann in Buch 7 mit der Verzögerung des Sonnenaufganges fortgesetzt]).

143. Sehen (videre) ist bei Vergil durch demens bestimmt als das des Wahns, aber dennoch hat Servius auch videt alleine als prägnante Bezeichnung eben dieses anderen Wahrnehmens gelesen (Serv. zu Aen. 4,469): et bene "videt agmina" expressit furentem, cum ait "videt", non "existimat", sed "putat se videre".

144. Grundlegend dazu Leigh (1997) 143-157, bes. 152-157 zum "synecdochic hero" Pompeius. Räumliche Erhebung als Entfernung soll den Figuren einen Überblick verschaffen (Feldherren, Anführer etc.), nicht selten wird aber das so erreichte Sehen zu einem visionären oder sogar von Wahnvorstellungen induzierten: Pompeius betrachtet von einer Anhöhe aus (7,649f. stetit aggere campi/ eminus unde [sc. aspiceret]) die Niederlage seines Heeres und, ohne daß ein Trennsignal zwischen Blick und Vision gegeben würde, wandelt sich ihm das Gesehene in eine Metapher seines eigenen (zukünftigen?) Erlebens: 7,652f. Tot telis sua fata peti, tot corpora fusa/ ac se tam multo pereuntem sanguine vidit. Durchgehalten haben sich die "Schreibweisen" der Ambiguität in der Phantastischen Literatur des 19. Jahrhunderts, für die Todorov (1975) 37 neben den Markierungen durch Verba des Sehens und Scheinens (lat. videri/videre) auch die Modalisation der Satzaussage (z.B. "vielleicht", in unseren Texten dubium est, forte etc.) und den Einsatz des Imperfekts (als Distanzierung zwischen dem früheren "Meinen” und dem Jetzt des Erzählens) genannt.

145. Zum Begriff s.u. das Zitat aus Rosenkranz (1853/ 1990) 262.

146. Die Nutzung der Motivik von "Schutz-Relationen" zwischen Göttern und Menschen weist wohl nicht auf eine Parodie, ist damit wohl auch keine Kennzeichnung der Erictho als «Pseudogottheit» (Verweise zur literarischen Tradition bei Korenjak [1996] 240 zu 6,829, «Pseudogottheit» hier und zu 6,625).

147. Vgl. Verg. Aen. 6,160f. multa inter sese vario sermone serebant/ quem socium exanimum vates, quod corpus humandum/ diceret.

148. Vgl. Verg. Aen. 6,158f. cui fidus Achates / it comes et paribus curis vestigia figit [Lucans tutos gressus], die Stelle nennen mehrere Gelehrte, u.a. Narducci [2002] 129, der, wie die übrigen, mit der Leitvorstellung des "rovesciamento" Vergils in den antagonistischen Modellen bleibt, das Zitat trägt die dunkle Stimmung des Vergilpassus in die lucanische Szenerie und verstetigt das Unheil (vgl. Aen. 6,157f. caecosque volutat/ eventus animo secum, die folgende Misenus-Episode etc.). $\mathrm{Zu}$ Cornelia vgl. das Ende des fünften Buches Bell. civ. 5,804f. fida comes Magni vadit duce sola relicto/ Pompeiumque fugit. Aus oben angeführter Begegnungsszene der Liebenden (Ov. her. 21) kann das Äquivalent der sedula nutrix für die Begleitung genannt werden. W. Görler verweist mich auf die ebenfalls deutlichen Entsprechungen zur Begleitung des Aeneas durch die Sibylle in Aen. 6,268 ibant obscuri sola sub nocte per umbram [...], ähnlich am Episodenende ebd. 898 prosequitur, auf das in klarem Kontrast zum lucanischen Entwurf (it comes) die Trennung von der Führerin als Szenenschluß folgt (Aen. 6,899 ille viam secat ad navis sociosque revisit).

149. Die Szenen "Caesar am Rubikon" (bzw. "Aeneas am Styx") hat Korenjak (1996) auch in 6,374. 624 und 777f. wiedergefunden (vgl. S. 43 Anm. 187 und jeweils ad loc.) und belegt mit der Intensität der Bezüge die Bezeichnung der Ericthoszene als einer "Pharsalia im Kleinen" (ebd. zu 6,777f.). Zur vergilisch-ovidischen Folie der Patria-Szene und ihrer metapoetischen Lektüre vgl. Maes (2005) 10-23, aber bereits Görler (1976) hatte hier entscheidende Beobachtungen zur narrativen Funktion vorgelegt. 
150. Die (entmutigend) dichten Verweisnetze, die eine Fülle von Figuren und Ereignissen des Bellum civile miteinander verbinden, sind also nicht in Analogien und Verweisrelationen auflösbar, sondern jeweils nur auf der Ebene der Veranschaulichung unterschiedene Erscheinungsweisen derselben Figuren der Entzweiung (aus der Fülle der bereits beschriebenen Entsprechungen seien nur wenige noch genannt: der zerrissene Körper und die Kopf-Metaphorik [caput]: der alte Mann sucht mit einem abgetrennten Kopf in der Hand nach einem passenden Körper [2,169-173 meque ipsum memini caesi deformia fratris/ ora rogo], damit das Pompeiusmotiv der rasenden Frau [mit deformis in 1,685] schon vor der Verwirklichung auf der Geschehensebene [Bell. civ. 8 und 9] wiederaufnehmend, die Vorstellung vom caput mundi bleibt an allen Stellen präsent [2,186f. unum/ tot poenas cepisse caput]. Sulla-Caesar-Identität über das Bild des Schauens 2,207f. Intrepidus tanti sedit securus ab alto/ spectator sceleris.

151. Bell. civ. 6,516-518 caeloque ignota sereno/ terribilis Stygio facies pallore gravatur/ inpexis onerata comis.

152. Zur Metamorphose als Stoizismus und seinen Implikationen auch Wildberger (2005) 76-82 und beeindruckend genau und aufschlußreich Brena (1999).

153. Rosenkranz (1853/ 1990) 262 ordnet die Begriffe "Gespenstisch", "Dämonisch" und "Diabolisch" als Relation zwischen der Verfaßtheit eines Willens und dessen Erscheinungsweise: "Weiß der Wille endlich sich als den prinzipiell bösen, der sich als den Schöpfer einer Welt des Nichts benimmt und daran seine widrige Freude hat, so wird er diabolisch. Ein solcher Wille ist in seiner Negativität zugleich dämonisch, und dies Dämonische ist in seiner Erscheinung das Gespenstische." In diesem Sinne ist Erictho als Figur die gespenstische Erscheinung eines dämonischen Willens zur inneren Entzweiung, der sich sowohl in Erictho als auch in den Figuren des Bürgerkriegs beschreiben läßt (zur besonderen Eignung der Hexenvorstellungen für die Umsetzung des diabolischen Willens, der sich der affirmativen Weltordnung entgegenstellt, in die Erscheinungsweise des Gespenstischen vgl. Rosenkranz ebd. 294).

154. Die Vorstellungswelten der semidei manes und der dämonischen Wesen in stoischer Lehre hat Brena (1999) 287f. schlüssig vorgestellt (in Hinsicht auf das Schicksal der Seele des lucanischen Pompeius), so daß eine solche Erscheinungsweise der Patria (über die Brücken der Personifikation und der Traumbilder) nichts Überraschendes besitzt.

155. Die Ekstase der Erictho aus der poetischen Abstraktion Thessaliens, dessen hauptsächliches Kennzeichen die Identität von erfahrungsweltlich getrennten Kategorien darstellt exemplifziert an den Grenzauflösungen zwischen Ober- und Unterwelt sowie zwischen Ereignisund Erscheinungsebenen, wird im Abstieg der Figur auf die historische Geschehensebene und ihrem Aufgehen im römischen Lager nicht beendet, sondern verdauert, so daß ihre Wiederkehr in den späteren Büchern zu untersuchen wären (den Vorgang der Ekstase beschreibt der Sprecher im Anatomischen in 9, 792 tendit ... cutem pereunte figura ... tumor). Auch die zahlreichen weiteren Verweise auf die Trennungsvorstellung (weniger von der Seelenwanderung als von der Trennung und dem Problem des sich über Grenzen hinweg Durchhaltenden) müßten auf die Ausarbeitung des poetischen Konzepts hin untersucht werden (als Beispiel sei noch die poetologische Problematisierung in der Formulierung für das "Fortdauern" des Bildes (imago) des Pompeius in den Eingeweiden (viscera) der Cornelia genannt [Bell. civ. 9,71f. non imis haeret imago/ visceribus?]).

156. Gängige topologische Vorstellungen von der Textorganisation finden sich bereits in der Terminologie: digressio und excursus benutzen das impizite Bild vom Text/ Sprecher als einer sich im Raum bewegenden Entität, die "beiseite tritt", "herausläuft", "zurückkehrt" etc. 


\section{RÉSUMÉS}

Im Ausgang von der Möglichkeit, mit dem Wort figura Gestalten der Handlungsebene, dynamisch gefaßte Gedanken- / Wortgebilde und Erscheinungsweisen von Phänomenen geistiger und materieller Natur zu bezeichnen, läßt sich das Bellum civile als Werk beschreiben, an dessen Grund die Figur der Entzweiung steht, die durch eine Poetik der Emergenz in den Stoff entfaltet wird. Die vorgeschlagene Lektüre des Bellum civile wendet sich damit gegen das verbreitete Verständnis des Textes als eines (politischen, moralischen) Kommentars zum Bürgerkrieg und kehrt die Hierarchie um: Der (sekundäre) Bürgerkriegsstoff soll die zugrunde liegende Figur der Entzweiung explizieren, wird von dieser aber nicht gedeutet, sondern benutzt. Emergenz tritt als poetische Verhältnisbestimmung an die Stelle chronologischer und kausaler Erklärungsmodelle und behauptet eine bleibende Verbindung von Untergrund und hervortretendem Relief (Ereignis, Wesen, Gestalt). Dementsprechend lassen sich die Gestalten der Handlungsebene (figurae) als Ekstasen des Textes fassen, die in einer Verdichtung des Textes aus dessen Oberfläche hervortreten, zugleich gemeinsam mit anderen Textelementen Erscheinungsweisen (figurae) der abstrakten Figur der Entzweiung sind. Im sechsten Buch des Bellum civile wird die Ekstase insbesondere im Hervorgehen der Erictho aus der Konstruktion eines raum-zeitlich unmöglichen Thessalien kompositionell konkretisiert und imitationstechnischumgesetzt: Die ovidisch geprägte Begegnungsszenezwischen Sextus Pompeius und der textuell übercodierten Erictho bereitet den Boden für die Auffassung der Hexesowohl als einer Fortschreibung der nach Ovid vergehenden Sibylle als auch als figura (Gestalt und Erscheinungsweise) Roms, das sich in einer Trennung von sich selbst gegenübertritt und im (poetischen) Kannibalismus die Entzweiung zumVollzug bringt.

\section{INDEX}

Mots-clés : Lucan, Rezeption Ovids, Erictho, figura, Verstummen der Sibylle, Emergenz, Verdichtung des Textes, Kausalität, literarische Figuren, Poetik, Entzweiung, Thessalien, Landschaftsbeschreibung, Roma

\section{AUTEUR}

\section{ALEXANDER ARWEILER}

Universität von Münster 